\title{
WestVirginiaUniversity
}

THE RESEARCH REPOSITORY @ WVU

Graduate Theses, Dissertations, and Problem Reports

2018

\section{The Effects of E-Cigarette Exposure on the Peripheral Vasculature}

Christopher Pitzer

Follow this and additional works at: https://researchrepository.wvu.edu/etd

\section{Recommended Citation}

Pitzer, Christopher, "The Effects of E-Cigarette Exposure on the Peripheral Vasculature" (2018). Graduate Theses, Dissertations, and Problem Reports. 7229.

https://researchrepository.wvu.edu/etd/7229

This Thesis is protected by copyright and/or related rights. It has been brought to you by the The Research Repository @ WVU with permission from the rights-holder(s). You are free to use this Thesis in any way that is permitted by the copyright and related rights legislation that applies to your use. For other uses you must obtain permission from the rights-holder(s) directly, unless additional rights are indicated by a Creative Commons license in the record and/ or on the work itself. This Thesis has been accepted for inclusion in WVU Graduate Theses, Dissertations, and Problem Reports collection by an authorized administrator of The Research Repository @ WVU. For more information, please contact researchrepository@mail.wvu.edu. 
The Effects of E-Cigarette Exposure on the Peripheral Vasculature

Christopher Pitzer

Thesis submitted to the School of Medicine, Division of Exercise Physiology at West Virginia University in partial fulfillment of the requirements for the degree of Master of Science in Exercise Physiology

Randall W. Bryner, Ed.D.

Paul D. Chantler, Ph.D.

I. Mark Olfert Ph.D., Chair

Division of Exercise Physiology

Morgantown, West Virginia

2018

Keywords: cytokine, E-cigarettes, Electronic Cigarette, vasculature, Vessel Tone

Copyright 2018 Christopher R.L. Pitzer 


\section{Abstract \\ The Effects of E-Cigarette Exposure on the Peripheral Vasculature}

\section{Christopher Pitzer}

E-cigarettes have emerged as popular alternatives to traditional smoking, partially because of efforts of manufacturers to portray them as safe. Recent studies have cast doubt on claims of safety, our lab has published data showing a significant impairment in endothelium-dependent dilation with chronic exposure, however the acute temporal effects and mechanisms involved with E-cigarette exposure on the vasculature are still poorly characterized. This study uses an intravital microscopy approach to evaluate the effects of acute time course changes following E-cigarette vapor exposure on second-order arterioles in the gluteus maximus muscle of mice. We hypothesized that endothelial impairment would be observed with a single E-cigarette exposure. C57BL/6 mice were anesthetized and a portion of the gluteus maximus muscle was externalized to allow visualization of second order arterioles. Arteriolar tone was monitored for up to 120-minutes in one study to determine the effects of E-cigarette exposure. In a separate study, vascular function was assessed by dilation to acetylcholine 50 minutes after exposure to a single 5-minute (10 puff) exposure to E-cigarette vapor. Significant vasoconstriction occurred in E-cigarette exposed animals with or without nicotine using 50:50 vegetable glycerin/propylene glycol (VG/PG-18 and VG/PG-0, respectively, $p<0.05$ ), as well as in animals exposed to $100 \%$ PG with no nicotine (PG-0) and 100\% VG with no nicotine (VG-0). E-cigarette responses were similar to animals exposed to traditional tobacco-based 3R4F reference cigarette (3R4F). No significant differences in vessel response to acetylcholine pre- vs. postexposure were generally found; except with VG/PG-18, which showed significant increase in acetylcholine curve slope after vaping. Assessment of growth factor and cytokines response following chronic (8-month) exposure to E-cigarette exposure was obtained from a separate study which we have previously show impaired vascular function (Olfert et al. 2018). Cytokine quantification was performed using a multiplex kit from Meso-Scale Discovery (Rockville, MD, US) on homogenates of lung, gastrocnemius muscle, serum and bronchoalveolar lavage fluid (BALF) in C57BL/6 mice exposed to filtered room air (AIR), 3R4F cigarette, and Cappuccinoflavored E-cigarette vapor (E-CIG, 50:50 VG/PG). IL-6 in the serum of E-CIG animals was significantly lower than AIR animals $(P<0.05)$. VEGF tended to be lower in BALF and lungs of ECIG animals relative to air controls. Granulocyte-macrophage colony stimulating factor (GMCSF) also tended to be lower in E-CIG animals relative to 3R4F and AIR animals. Collectively, our data shows that acute E-cigarette exposure causes peripheral constriction ( $20 \%$ ) of blood vessels independent of nicotine and suggests that the base components of E-liquid cause vasoconstriction to a similar degree. Endothelial dilatory capacity is largely unaffected by Ecigarette exposure after 1-hour following a single acute exposure. Chronic E-cigarette exposure alters the expression of IL- 6 in the serum and may affect expression of VEGF in the lungs and BALF and GM-CSF expression in the lungs. Taken together these data suggest that vaping has acute effects on the basal blood vessel tone that is similar to traditional cigarettes, suggesting the chronic E-cigarette use is likely to produce long-term vascular health consequences similar to that observed with cigarette smoking. 


\section{Table of Contents}

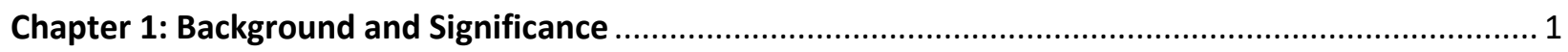

1.1 Overview of E-cigarette Function and Potential Toxicities .......................................................... 2

1.2 Comparison of toxicity of E-cigarettes and Traditional Cigarettes ................................................ 4

1.3 Effects of E-cigarettes on Immune System Function and Cytokine Expression............................... 9

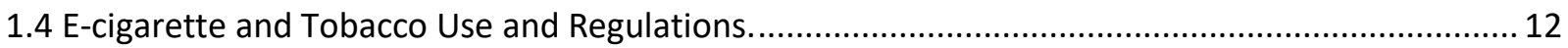

1.5 Effects of E-cigarettes and Traditional Cigarettes on Vascular Reactivity.................................... 13

1.6 Overview and History of Intravital Microscopy to Study the Vasculature and Effects of Smoking. 17

1.7 Factors Influencing Peripheral Vascular Tone and Potential Effects of E-cigarettes ....................... 19

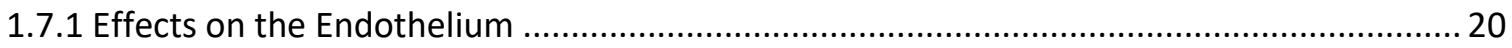

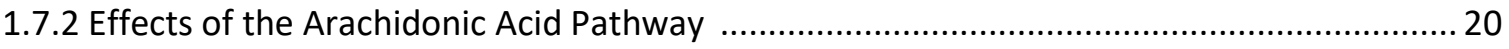

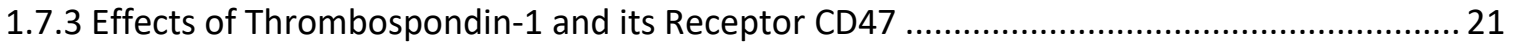

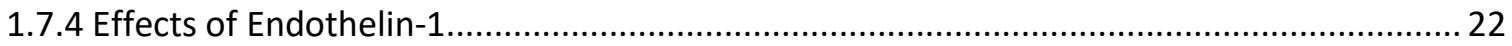

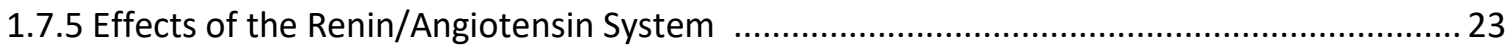

1.7.6 Potential Sympathomimetic Effects of Vapor Constituents ............................................ 24

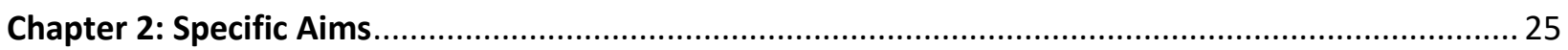

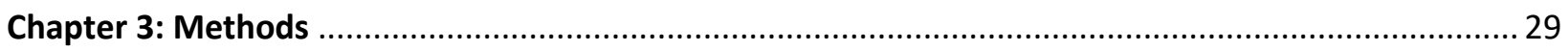

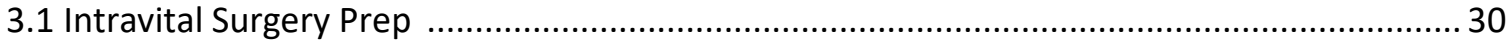

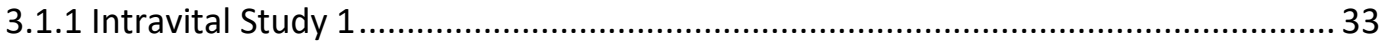

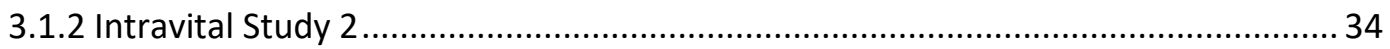

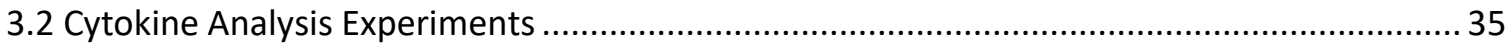

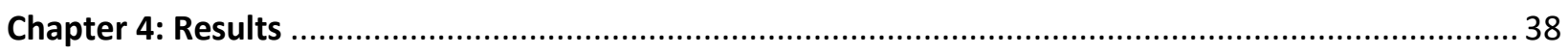

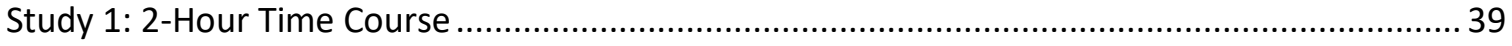

Study 2: Vascular Reactivity after 50-Minutes following Vaping .............................................. 44

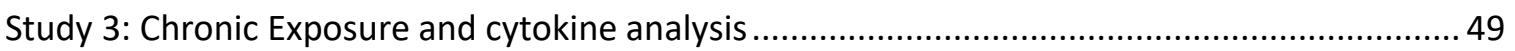

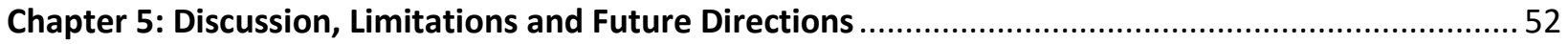

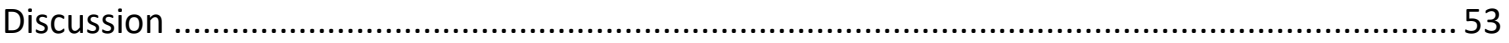

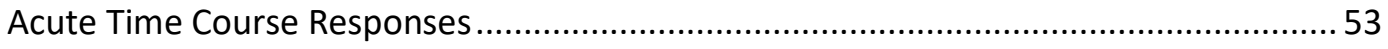

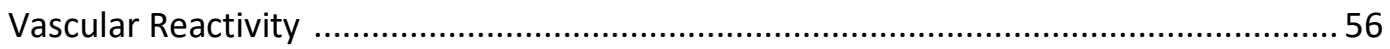

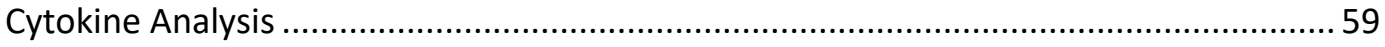




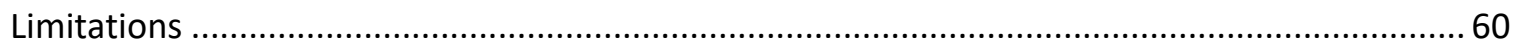

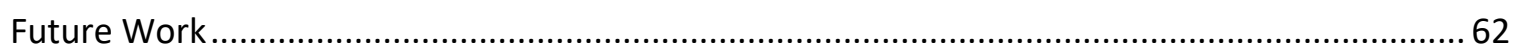

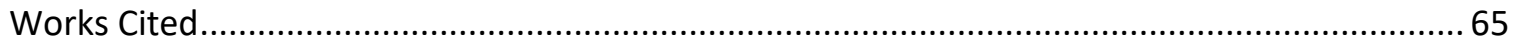


Chapter 1: Background and Significance 


\subsection{Overview of E-cigarette Function and Potential Toxicities}

Since they first appeared on the US market in 2006, E-cigarettes have evolved from disposable "cig-a-like" devices to refillable "tank style" devices (U.S. Food \& Drug Administration, 2016) (Figure 2.1). The evolution of E-cigarette products now includes larger "mods" devices with variable temperature, resistance and voltage settings. E-cigars and E-pipes have recently appeared in US markets but despite different appearances, function in the same manner as other E-cigarettes.

Despite the differences in appearance all E-cigarettes operate by heating a "base" mixture of propylene glycol and vegetable glycerin, that also contains flavoring and in most cases nicotine, to the point of evaporation allowing the user to inhale the aerosol (Ikonomidis et al., 2018). Different refill liquids for E-cigarettes are known to contain flavorings that upon heating can generate potentially toxic compounds, many of which are cytotoxic to endothelial cells(e.g. cinnamaldehyde) (Behar et al., 2014; P. W. Clapp \& Jaspers, 2017). Many devices offer

variable voltage or temperature settings which may change the composition of the aerosol with higher voltages generally resulting in higher concentrations of breakdown products (Kosmider et al., 2014).

It is believed that the breakdown of the base solvents during heating leads to the generation of carbonyl compounds that are known to be carcinogenic (Cassee et al., 2008; Tyihák, Bocsi, Timár, Rácz, \& Szende, 2001) It is also possible that with repeated heating, particles of metal from the atomizer become aerosolized and inhaled (Hess et al., 2017; Nayir, Karacabey, Kirca, \& Ozdogan, 2016). E-cigarette liquids themselves have also been shown to 


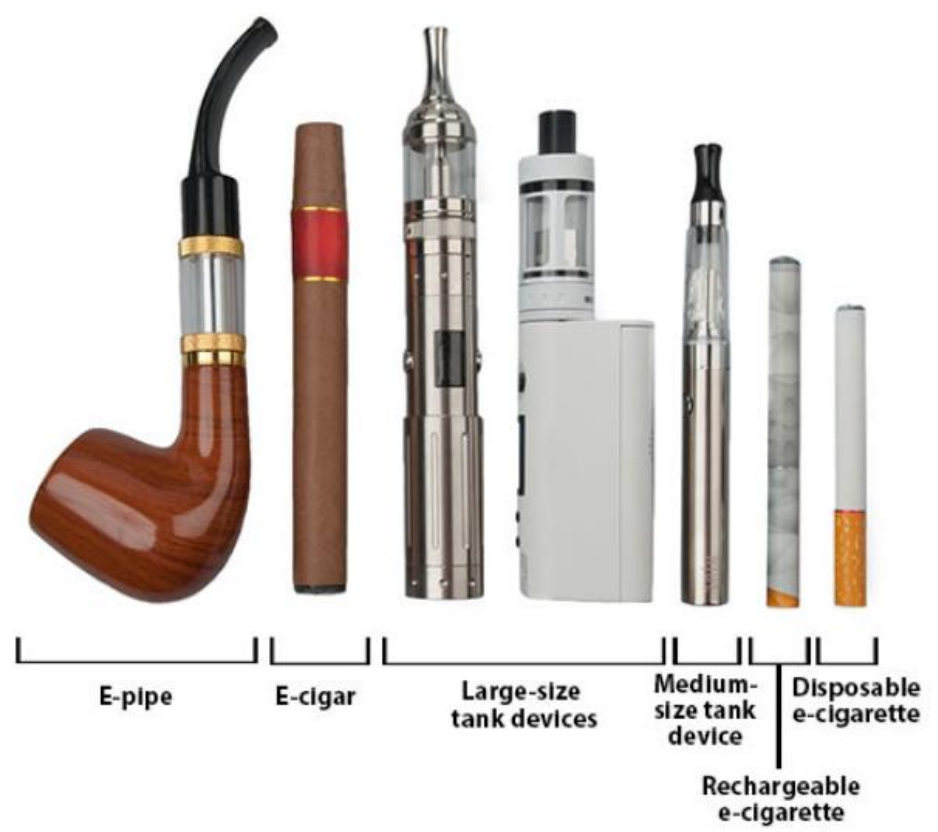

Figure 1.1: Image from CDC Surgeon General Report (Center for Disease Control and Prevention, 2011) depicting various E-cigarette devices of different generations.

contain nitrosamines, compounds that are inflammatory and carcinogenic (Farsalinos, Gillman, Poulas, \& Voudris, 2015; H. J. Kim \& Shin, 2013). Studies using cell culture techniques have shown that exposure to E-cigarette aerosol extract can suppress antioxidant defenses and increase oxidative DNA damage (Ganapathy et al., 2017). The decrease in antioxidant capacity and induction of DNA damage may be a potential mechanism for tumorigenesis.

E-cigarette liquid has also been shown to increase the rate of viral infection of cells that have been exposed to it (Wu, Jiang, Minor, \& Chu, 2014). Decreased immunity in the airways may lead to increased infection rates in the upper respiratory tract. This process is likely mediated through altered function of neutrophils, which have been shown to be activated in the lungs in response to E-cigarette vapor exposure (Hwang et al., 2016) as well as increased secretion of proinflammatory cytokines (Higham et al., 2016). 
An emerging body of evidence has shown that E-cigarette liquids are cytotoxic to human vascular endothelial cells (Anderson, Majeste, Hanus, \& Wang, 2016; Putzhammer et al., 2016). This toxicity is a likely mechanism of decreased endothelium dependent dilation seen with E-cigarette exposure studies (Carnevale et al., 2016; Olfert et al., 2018). It is also likely that endothelial cell toxicity can lead to the development of atherosclerosis by increasing endothelial permeability. One recent study shows that exposing human vascular endothelial cells to E-cigarette aerosol extract results in both apoptosis and programmed necrosis pathways leading to increases in DNA fragmentation (Anderson et al., 2016). These changes

were resolved upon treatment of cells with antioxidants (Anderson et al., 2016), suggesting that oxidative damage to endothelial cells is likely to lead to vascular impairment and an increased risk for CVD (Qasim, Karim, Rivera, Khasawneh, \& Alshbool, 2017).

\subsection{Comparison of toxicity of E-cigarettes and traditional cigarettes}

Determining the relative toxicity of E-cigarettes compared to traditional cigarettes has been a recent focus in the literature. Effects of E-cigarettes and traditional cigarettes on air quality is emerging as a public health concern. It is well documented that the vapor produced by E-cigarettes is less complex than smoke from combustible cigarettes (Carnevale et al., 2016; P. W. Clapp \& Jaspers, 2017). Decreased complexity does not simply equate to decreased toxicity however, as some compounds linked to E-cigarette vapor have been shown to be cytotoxic (Behar et al., 2014; Farsalinos, Gillman, et al., 2015). Other studies using ultra-high performance liquid chromatography tandem mass spectrometry (UHPLC-MS) methods have 
found concentrations of chemicals known to be corrosive or toxic in vapor extracts, these chemicals were not present in the liquid before vaporizing (Higham et al., 2016). Recent data has also shown that E-cigarette vapor exposure is linked to development of a COPD phenotype in mice in a nicotine dependent manner (Garcia-Arcos et al., 2016). This is likely due to the interactions of constituents of E-cig vapor with neutrophils present in the lungs (Higham et al., 2016).

The presence of formaldehyde and acetaldehyde has been demonstrated in both the smoke of traditional cigarettes and in E-cigarette vapor (Kosmider et al., 2014; Ogunwale et al., 2017; Wang et al., 2009). The relative quantities of toxic aldehydes in each remains controversial. While studies of early generation E-cigarette products showed greatly decreased aldehyde concentrations (Ogunwale et al., 2017), studies of newer variable temperature and voltage devices show that levels of aldehydes approach those of traditional cigarettes (Ogunwale et al., 2017). An argument proposed by Jensen et al. claims that a large portion of aldehydes present in E-cigarette vapor are "hidden" as aldehyde containing hemiacetals, which are broken down to formaldehyde in the body but undetected by traditional aldehyde detecting methods (Seifter, 2014). Experimental confirmation of this hypothesis is warranted, as aldehydes are highly toxic and high levels found in E-cigarette vapor would be a public health concern.

Proteomic analysis has shown that there are biological effects of aldehydes in the lungs of E-cigarette users. Reidel et al. have shown that E-cigarette exposure significantly increases expression of aldehyde detoxifying enzymes, oxidative stress response proteins, and matrix metalloproteinase-9 (MMP-9) in the sputum of E-cigarette users (Reidel et al., 2017; Reidel et 
al., 2010). The levels of these enzymes were comparable to those found in cigarette smokers, possibly indicating a nonlinear toxicity of reactive carbonyls in the lungs (if levels of the aldehydes are indeed lower in E-cigarettes). The other elevated proteins found in the secretomes of subjects in these studies are also important, oxidative stress as well as increased levels of MMP-9 are known to exacerbate development of the COPD phenotype (Mercer et al., 2005).

From a vascular perspective, the amount of oxidative stress E-cigarettes cause is somewhat controversial. Ikonomidis et al. have shown that arterial stiffness and markers of oxidative stress are decreased with use of E-cigarettes when compared to traditional cigarettes (Ikonomidis et al., 2018). Other studies have however shown that particulate matter of similar size to that found in E-cigarettes can cause rapid and lasting cardiovascular toxicity via oxidative mechanisms (Brook et al., 2002; Kampfrath et al., 2011).

Analysis of particulate matter emitted from E-cigarettes has shown that the number of particles inhaled from a puff of an E-cigarette are approximately equal to, if not slightly greater than those of a traditional cigarette (Ingebrethsen, Cole, \& Alderman, 2012; Thorne et al., 2016). There is less consensus in determining the mutagenic potential of those particles.

Thorne et al. have shown that E-cigarette aerosol is not mutagenic to two different strains of Salmonella typhimurium (Thorne et al., 2016). This contradicts the findings of Ganapathy, who found a potential mechanism of mutagenesis via suppression of antioxidant defenses and induction of oxidative DNA damage to cultured human mouth and lung epithelial cells (Ganapathy et al., 2017). These results, while interesting, may not be appropriate for determining mutagenic capacity, as Ganapathy et al. (while using human cells) did not attempt 
to match for an average exposure of those cells in realistic use. The concentrations these cells were exposed to may have been higher doses than mouth or lung epithelium would realistically be exposed to even with regular use. The overall mutagenic capacity of E-cigarettes in real use situations is still unclear, and thus real comparisons to traditional cigarettes is still poorly understood.

Studies comparing the effects of E-cigarette and traditional cigarette on indoor air quality have also yielded conflicting results. McAuley et al. found no immediate risk to human health from E-cigarette emissions in their study which used a 40-cubic meter room as an exposure chamber while testing for compounds traditionally found in secondhand smoke (McAuley, Hopke, Zhao, \& Babaian, 2012). In a study with a 45-cubic meter exposure chamber, Schober et al. found significantly elevated levels of 1,2-propanediol, nicotine, glycerin and aluminum. 1,2-propanediol is of particular concern in this study as particles from secondhand exposure may deposit in the lungs, where irritation may occur (Schober et al., 2014). Another study, which took air samples before and during an E-cigarette convention (room volume 4023 cubic meters) found 125-330 times higher levels of particulate matter smaller than 2.5 micrometers during the event (Soule et al., 2018). Inhalation of particulate matter of this size distribution has been linked to acute cardiovascular dysfunction (Brook et al., 2002). Overall, the effects of secondhand E-cigarette exposure poorly characterized and more research is warranted to determine safety and inform policy decisions.

Because of marketing campaigns suggesting that E-cigarettes are safe, or safer, relative to combustible cigarettes, and recommendations of other governments to reduce harm by replacing cigarettes with E-cigarettes, the use of E-cigarettes as a smoking cessation aid has 
been suggested (Brown, Beard, Kotz, Michie, \& West, 2014; Christopher Bullen et al., 2013;

Orellana-Barrios, Payne, Medrano-Juarez, Yang, \& Nugent, 2016). E-cigarettes are not, however approved as cessation aids in the United States by the FDA, due largerly to a lack of literature definitively illustrating E-cigarettes as safer alternatives and the publication of studies showing that E-cigarettes are likely minimally effective in promoting cessation (Brown et al., 2014; Caponnetto et al., 2013; Orellana-Barrios et al., 2016). Bullen et al. have shown that participants reported a significant decrease in satisfaction using E-cigarettes compared to traditional cigarettes (C. Bullen et al., 2010). This is an important result, as behavioral analysis of individuals who smoke, even those who desire to quit, report satisfaction with the act of handling and lighting traditional cigarettes (Jarvis, 2004). The absence of the rituals (handling boxes, lighting the cigarette, etc.) that cigarette smokers have become attached to may decrease the efficacy of E-cigarettes as smoking cessation tools.

Overall, the comparison of traditional combustible cigarettes to E-cigarettes is not likely an "apples to apples" comparison. The variability of E-cigarette device settings as well as the number of brands, flavorings and base liquid mixtures presents a degree of difficulty in comparing E-cigarettes to traditional cigarettes. Studying the biological effects of E-cigarettes is also difficult since the effects of each variable component of E-cigarettes on vapor content and biological activity is poorly understood. E-cigarettes are also not recommended as replacements for traditional cigarettes because there is a lack of evidence that they are effective cessation tools, some studies even report a "dual use" effect where users maintain daily cigarette intake and use E-cigarettes also (Correa et al., 2018; Orellana-Barrios et al., 2016). 


\subsection{Effects of E-cigarettes on Immune System Function and Cytokine Expression.}

The relative newness of E-cigarettes ( $<12$ years) makes the study of long-term effects on humans difficult, in part, because smoking-related heart disease and COPD is often found only after several decades of exposure. This has made animal models and cell culture experiments increasingly important to gain early insight in determining potential risks with chronic ECigarette before decades must pass for us to understand the consequences vaping of humans. Because the lungs are the primary site of contact, studies of pulmonary immunity have been a recent priority of the literature (Hwang et al., 2016; Sussan et al., 2015; Wu et al., 2014). Cell culture studies are also valuable for this process also as they allow for precise control of exposure dose and monitoring of the response of individual cell populations.

Pulmonary injury is a major concern of current E-cigarette research. Recent data has linked E-cigarette exposure to an increase in Th2 cytokines (Interleukins 4,5,10 and 13 (Barnes, 2001)) in the lungs. Th2 cytokines are thought to be responsible for sensitization of the lungs and a potential cause of asthma (P. W. Clapp \& Jaspers, 2017). Development of asthma is of particular concern among younger users, the US Surgeon General reports that use of Ecigarettes among middle school students is approximately equal to use among adults over 25 (US Department of Health and Human Services, 2017). E-cigarette exposure in mice has also been shown to induce a COPD phenotype in a nicotine-dependent manner (Garcia-Arcos et al., 2016). The progression of COPD has been shown to worsen through increases in proinflammatory cytokines, mostly coming from neutrophils (neutrophil associated cytokines include IL-8, leukotriene B4 and tumor-necrosis-factor-alpha, TNF- $\alpha$ ) (Reid \& Sallenave, 2003). E-cigarette use has also been shown to increase presence of neutrophils in the lung (Boris 
Reidel, Giorgia Radicioni, Phillip Clapp, Amina A Ford, Sabri Abdelwahab, Meghan E Rebuli, Prashamsha Haridass, Neil E Alexis \& Kesimer, 2010; Hwang et al., 2016) and increase the inflammatory response of the neutrophils (Higham et al., 2016) pointing to a possible concern of COPD development in chronic users.

Altered immune cell expression in the lungs also results in altered immune system efficiency. Exposure to E-cigarette exposure in mice has been shown to increase presence of bacterial colonies (Hwang et al., 2016). This is likely due, at least in part, to a decrease in phagocytosis of macrophages caused by E-cigarette exposure (Sussan et al., 2015). Studies have also shown increased rates, duration and severity of viral infection upon exposure to E-cigarette vapor (Sussan et al., 2015; Wu et al., 2014). Increased infection and duration may also play a role in the pathogenesis of the COPD phenotype, increasing neutrophil presence in the lung (and as described above has been linked to decreased activity of NK cells (PRIETO et al., 2001) as well as decreased phagocytic activity (Drannik et al., 2004)). This dysfunction in the immune system may lead to exacerbations of COPD, leading to reductions in lung function which is an important cause of death of patients with COPD (Hoenderdos \& Condliffe, 2013).

While there is little data available in the context of E-cigarettes' effect on cytokine expression, the effects of cigarettes are well characterized. Likely the first proinflammatory mechanism to be activated upon inhalation of cigarette smoke is the NF-kB pathway. NF-kB has been shown to increase the release of IL-8 as well as TNF- $\alpha$ (Yang et al., 2006). While the direct effects of E-cigarettes on NF-kB have yet to be directly studied, chemicals commonly used to flavor E-cigarettes have been shown to significantly increase IL-8 production in cultured monocytic cell lines (Muthumalage et al., 2018). This finding is interesting because the isolated 
flavoring chemicals were used rather than whole base liquids, meaning the increases in IL-8 happen independently of nicotine concentration. NF-KB has also been shown to modify histone de-acetylases after transcription (Yang et al., 2006), this is likely to increase the period of time that proinflammatory genes remain upregulated after exposure to inflammatory stimuli. While it is likely that E-cigarette flavorings increase IL-8 secretion through an NF-KB dependent mechanism this has yet to have been experimentally confirmed, further study is necessary to determine the effects of E-cigarettes on NF-KB and the cytokines that it promotes.

One of the most potent inflammatory mediators in acute cigarette exposure is TNF- $\alpha$. Churg et al. have shown that TNF- $\alpha$ is necessary for the alteration of gene expression and onset of tissue breakdown associated with acute cigarette exposure (Churg, Dai, Tai, Xie, \& Wright, 2002). TNF- $\alpha$ has also been shown to increase levels of membrane metalloproteinase enzymes, which are known to cause vascular remodeling and affect wound healing (Han, Tuan, Wu, Hughes, \& Garner, 2001). Caspase enzymes, which have been shown to increase levels of endothelial apoptosis, also have been shown to increase with elevated levels of TNF- $\alpha$ (Csiszar, Ungvari, Koller, Edwards, \& Kaley, 2004). It is important to note that endothelial cell apoptosis is likely to increase systemic circulation of IL-8 which is a potent neutrophil chemotactic factor, and since neutrophils can secrete TNF- $\alpha$ a positive feedback loop consisting of neutrophilia, TNF- $\alpha$ secretion, caspase activation and IL- 8 secretion is not difficult to imagine regarding cigarette and E-cigarette exposure. 


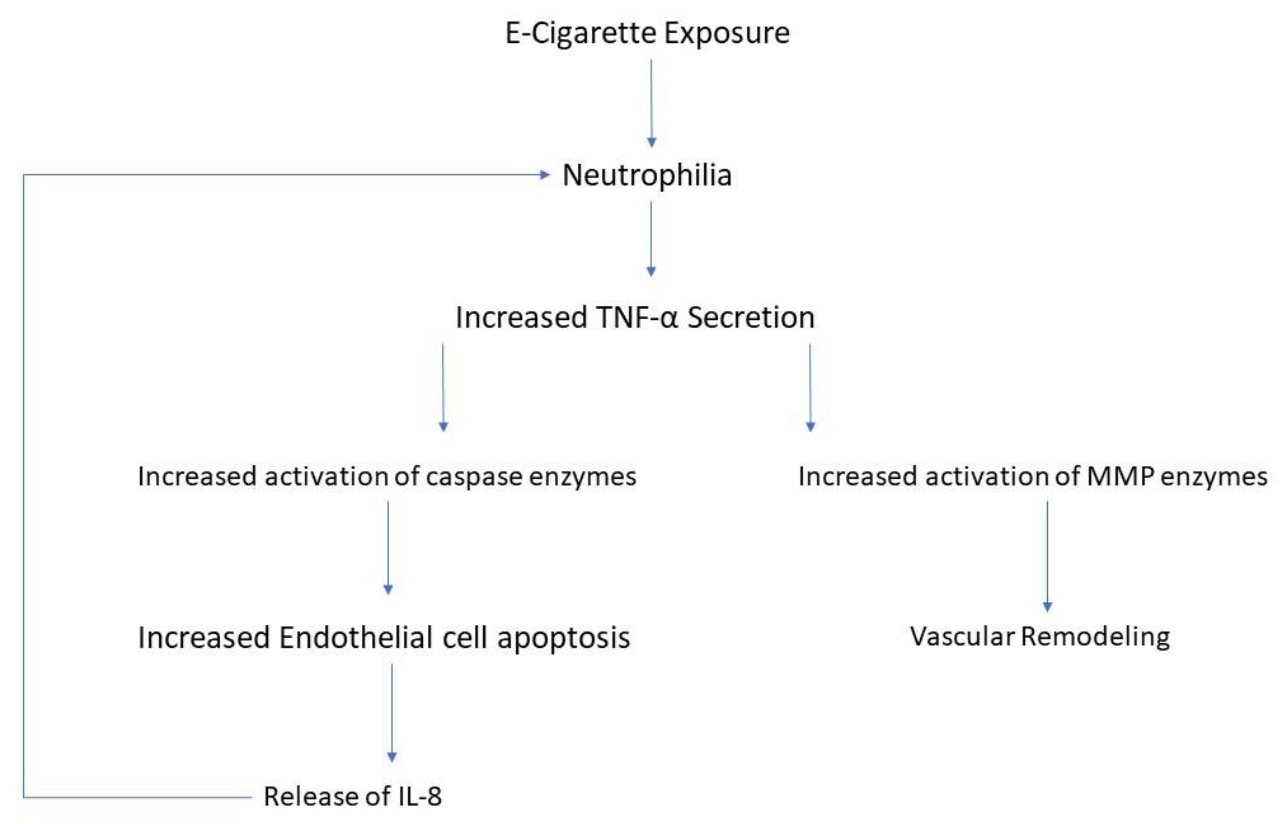

Figure 1.2 shows a potential mechanism of positive feedback following E-cigarette exposure. In this mechanism E-cigarette exposure drives neutrophil infiltration of the lungs and stimulates secretion of TNF- $\alpha$, which through a caspase enzyme mediated mechanism drives endothelial cell apoptosis and causes increased secretion of IL-8. IL-8 drives further neutrophilia of the lung by its action as a chemotactic factor.

\subsection{E-cigarette and tobacco use and regulations}

In 2016 the FDA expanded its definition of "tobacco products" to include E-cigarettes, liquids, and atomizers (U.S. Food \& Drug Administration, 2016). Emerging concerns about the quality and manufacturing of E-cigarettes and E-liquids has led to manufacturing regulations of E-cigarette products effective beginning August 2018, as well as age restrictions to purchasing E-cigarette products (U.S. Food \& Drug Administration, 2016).

Marketing campaigns by E-cig manufacturers portray their devices as "safe alternatives" to traditional cigarettes, but the good news is that a majority (72\%) of Americans recently 
surveyed believe that E-cigarettes will harm the health of users ("American S' Perspectives on E-Cigarettes," 2015). When considering the public opinions surrounding E-cigarettes, it is not surprising that 5 US states and over 400 counties have laws prohibiting the use of E-cigarettes indoors and other places where traditional smoking is prohibited ("American S' Perspectives on E-Cigarettes," 2015). Other public health concerns surrounding E-cigarettes are also present; for example studies have shown that inaccurate nicotine content has been found with E-liquid manufacturing (Buettner-Schmidt, Miller, \& Balasubramanian, 2016; Castranova, Asgharian, Sayre, Virginia, \& Carolina, 2016). Childproof containers are also infrequently used to contain Eliquid, this is of concern because fatal amounts of nicotine may be absorbed through the mouth or skin of a child (Buettner-Schmidt et al., 2016). One such death in the United states, in 2014, has prompted several states to adopt legislation requiring manufacturers to use childproof containers package their products (Frey \& Tilburg, 2016).

\subsection{Effects of E-cigarettes and traditional cigarettes on vascular reactivity}

Cigarette smoke has long been associated with vascular dysfunction (Lehr, 2000), the superoxide anion produced while smoking is thought to play a role in decreasing nitric oxide (NO) availability and damaging the endothelial cells that produce NO (Raij, DeMaster, \& Jaimes, 2001). One of the most common means of testing endothelial function is testing reactivity to acetylcholine. Acetylcholine interacts with soluble guanylyl cyclase to increase concentration of cyclic guanylyl monophosphate (cGMP); increases in cGMP causes stimulation of endothelial nitric oxide synthase (eNOS) and through a calcium dependent mechanism causes release of 
endothelium derived relaxing factors (EDRF) that cause relaxation of vascular smooth muscle cells(Thomsen, Rubin, \& Lauritzen, 2000).

Reactivity of blood vessels to acetylcholine is often used as a measure of vascular health (Figure 2.3). Lekakis et al. have shown that acute cigarette smoke exposure alters endothelial function in humans (Lekakis et al., 1997). While it is known that conditions such as hypoxia and inflammation may decrease the ability of the endothelium to produce NO (B. R. Clapp et al., 2004; Jeremy, Yim, Wan, \& Angelini, 2002), there are few studies detailing the effects of acute E-cigarette exposure on endothelial function. It is however known that pulmonary exposure to cigarette smoke increases activity of nicotinamide adenine dinucleotide phosphate (NADPH) oxidase (an enzyme responsible for the generation of free radicals) (M. Kim, Han, \& Lee, 2014).

NADPH oxidase is responsible for the generation of the superoxide ion, a free radical that has been shown to preferentially react with nitric oxide to form peroxynitrite (Beckman \& Koppenol, 1996). Excess peroxynitrite in the vasculature is associated with a decrease in dimerization of eNOS and a shift towards the production peroxynitrite by the eNOS enzyme itself in a process called eNOS uncoupling (Förstermann \& Münzel, 2006). eNOS uncoupling is likely caused by the oxidation of tetrahydrobiopterin (BH4), a cofactor of eNOS that causes dimerization. BH4 is oxidized by peroxynitrite quickly in the endothelial cells (Kuzkaya, Weissmann, Harrison, \& Dikalov, 2003). Asano et al. have shown that NADPH oxidase activity (and presumably endothelial uncoupling) is significantly elevated upon exposure to nicotine and tar free cigarette smoke extract (Asano et al., 2012). While nicotine is not required for NADPH oxidase activity to be upregulated there is also an experimentally determined role of nicotine in this pathway; fang et al. have shown that inhibition of NADPH oxidase improves vascular 
reactivity with chronic intraperitoneal injections of nicotine (Fang, 2006). These results are important when considering the potential impact of E-cigarettes on vascular reactivity, while nicotine may play a role in exacerbating NADPH oxidase activity, particulate matter emitted from E-cigarettes is also likely to play a role in NADPH oxidase upregulation and therefore vascular dysfunction (Kampfrath et al., 2011). This implies that E-cigarettes containing zero nicotine are also likely to decrease vascular reactivity.

Shown in Figure 2.3, calcium-dependent and -independent mechanisms of NO synthesis by the endothelium. The effects on this pathway as described above relate only to the calcium dependent mechanisms. The rightmost depiction in the figure illustrates the mechanism of vascular smooth muscle constriction to acetylcholine when the endothelium is damaged.

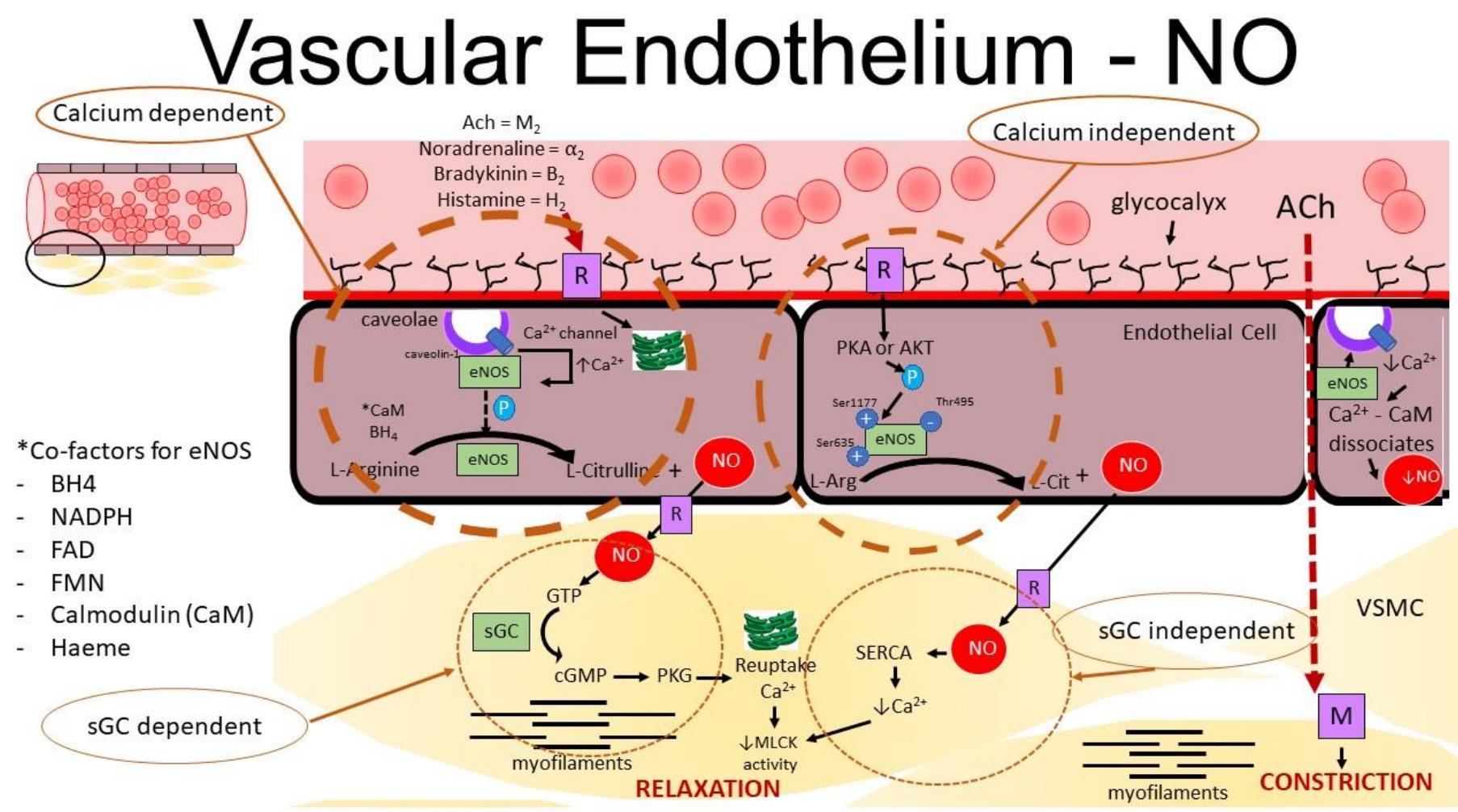

Figure 1.3 shows the calcium dependent pathway of NO synthesis (the pathway through which acetylcholine acts), the calcium independent pathway of NO synthesis and the mechanism by which acetylcholine can cause vasoconstriction when vascular endothelium is damaged. 
The calcium-independent pathway of NO synthesis involves the distension of the glycocalyx that lines the luminal surface of endothelial cells. As shown in Figure 2.3 the distension of glycocalyx branches causes activation of eNOS independently of calmodulin in the endothelium. Blood viscosity is important in the generation of NO in this manner and cigarette smoking has been shown to increase blood viscosity and decrease the ability of blood to exert sufficient shear stress on the glycocalyx to stimulate eNOS(Original Article, 2011). The effects of cigarette smoking on blood viscosity are likely due to increases in fibrinogen (Haustein, Krause, Haustein, Rasmussen, \& Cort, 2002). The effects of E-cigarettes on blood viscosity have yet to be studied, further research is needed to determine if E-cigarette exposure will affect eNOS activity in this way.

Apoptosis of endothelial cells is another potential mechanism of dysfunction, especially in the context of chronic use of cigarettes and E-cigarettes; endothelial cells can undergo a specific type of apoptosis called anoikis, in which the cells detach from the extracellular matrix and enter circulation (Boos, Balakrishnan, Blann, \& Lip, 2008). Raveendran et al. showed that priming endothelial cells to secrete NO had a protective effect on the cells upon exposure to cigarette smoke (Raveendran et al., 2005). This means that oxidative damage to endothelial cells by cigarettes or E-cigarettes may be prevented at the expense of NO bioavailability in vivo. Further oxidative stress on the endothelium may occur as the neutrophil response to Ecigarettes occurs, proinflammatory cytokines secreted by neutrophils may also effect NO bioavailability (B. R. Clapp et al., 2004) and endothelial cell apoptosis.

Vasomotor impairment caused by endothelial dysfunction is a precursor to CVD, cigarette smoke has been shown to cause endothelial dysfunction and vasomotor impairment 
(Celermajer et al., 1993; Raij et al., 2001; Rubenstein, Yong, Rennard, \& Mayhan, 1991; With \& Artery, 2018). The effects of E-cigarette exposure on the endothelium is not as well characterized, however a recent study from our laboratory has found chronic exposure to vapor has been shown to decrease endothelial dependent dilation in the aorta of mice (Olfert et al., 2018). This is important to consider when evaluating the safety of E-cigarettes as it implies a state of increased oxidative stress on the vasculature, which is known to decrease endothelial function, and lead to disease states such as atherosclerosis, coronary artery disease and heart failure (Anderson et al., 2016; B. R. Clapp et al., 2004; Kitta et al., 2009). The acute and chronic effects of E-cigarettes on vascular structure and function need further study, particularly toward the risk endothelial cells pose for development of CVD with chronic use.

\subsection{Overview and History of Intravital Microscopy to Study the Vasculature and Effects of Smoking}

Intravital microscopy is a procedure in which a living system is visualized while the organism being studied is still alive. These techniques have long been used to characterize the effects of toxicants on the vasculature and on the circulating immune cells. The body of literature concerning traditional cigarettes and isolated nicotine from an intravital perspective is quite robust (Álvarez et al., 2004; Kubes, Suzuki, \& Granger, 1991; Lehr, 2000; Lehr, Frei, \& Arfors, 1994; W G Mayhan \& Sharpe, 1998; William G. Mayhan, 1999; Rubenstein et al., 1991), there is however minimal data concerning E-cigarettes in this capacity. 
By the 1960's scientists established a link between smoking and heart disease (William, Thomas, Sandra, Doyle, \& Dawber, 1964). To address this issue and elucidate mechanisms, intravital studies became a popular means of visualizing the vasculature, and the cells it contains. Through these studies, investigators found a decrease in endothelium dependent dilation (Ambrose \& Barua, 2004; Anderson et al., 2016; Raij et al., 2001; Rubenstein et al., 1991), as well as an increase in leukocyte adhesion and rolling along venules ("CIGARETTE SMOKE ELICITS LEUKOCYTE ADHESION TO," n.d.). Leukocyte adhesion and rolling is an important part of the inflammation response, in response to inflammatory stimuli endothelial cells will express chemoattractant molecules on their surface. This allows the leukocytes to follow the chemoattractant molecules to the site of cellular injury where they can exit the vasculature and act inside the inflamed tissue (Yong, Zheng, \& Linthicum, 1997). Leukocyte adhesion and rolling is shown to occur in both arterioles (Álvarez et al., 2004) and in venules (Kubes et al., 1991; Lehr et al., 1994; Yong et al., 1997). Intravital studies also have shown that the increased leukocyte adhesion and rolling is likely due to oxidative mechanisms as treatment with superoxide dismutase( Reactive oxygen Species \& Hepatocytes, 2004) and vitamin C (Lehr et al., 1994) before exposure to cigarette smoke decreases leukocyte adhesion and rolling.

While there is currently no published data (that we are aware of) detailing the effects of E-cigarettes from an intravital perspective, there is available data concerning the effects of nicotine. Most intravital studies focusing on nicotine use an IV administration paradigm, this allows the concentration of nicotine in the blood to be precisely controlled. A study by Mayhan showed an increase in constriction to norepinephrine in vivo using this paradigm (William G. Mayhan, 1999). The results of this study are particularly important, as nicotine is known to have 
sympathomimetic effects, some mediated through norepinephrine, and the increased levels of constriction may play a role in nicotine-induced pathogenesis of cardiovascular disease.

The effects of nicotine on basal vascular tone are somewhat controversial. Some studies have found that nicotine is vasodilatory (Hilton, 1954) while others have shown no effect on vascular tone (Odginai Article, 1992). Black, et al. have shown that nicotine increases the vasoconstriction response of the peripheral vasculature this effect may be partially responsible for the confusion of the effects of vascular tone in vivo (Black et al., 2001). Despite the effects of nicotine on basal vascular tone remaining unclear, nicotine is only a fraction of the constituent compounds in E-cigarette vapor and further study to determine the effects of commercially available E-cigarette vapor is justified.

\subsection{Factors Influencing Peripheral Vascular Tone and Potential Effects of E-cigarettes.}

Peripheral arterioles in the skeletal muscle, and more specifically their diameter, can be used as a measure of the amount of blood flow to the muscle. The diameter of a vessel is proportional to the force exerted by the smooth muscle and is often referred to as "vessel tone". Second order arterioles (2A's) are generally used for measuring blood flow to an organ or muscle as they are downstream of major resistance arterioles, though they do provide some resistance (Bearden, Payne, Chisty, \& Segal, 2004). There are several potential effects of E-cigarettes on the $2 A^{\prime}$ s including: acute and chronic effects on the endothelium, stimulation of arachidonic acid pathway metabolites, the NO pathway, the actions of endothelin-1, the renin/angiotensin 
system and sympathomimetic effects of vapor constituents. For the sake of clarity, each of these potential effects will be discussed separately in their own subsection.

1.7.1 Effects on the Endothelium. Endothelial cells, which line the lumen of the vasculature have emerged as important potential therapeutic targets, in large part due to their production of NO. NO plays a role in maintaining vessel diameter as well as in anticoagulation, leukocyte adhesion and proliferation of vascular smooth muscle cells (Gewaltig \& Kojd, 2002). NO also plays a role in antioxidant capacity, partly because the NO molecule is itself a free radical which allows it to rapidly pair with any unpaired electrons in circulation (Jeremy et al., 2002). It is possible that an increase in free radicals associated with E-cig usage can sequester available NO in the vasculature and effect vessel tone acutely. These acute effects may also be compounded by chronic use as E-cig liquid extracts have been shown to be toxic to endothelial cells in culture and may cause apoptosis of endothelial cells via an oxidative mechanism (Anderson et al., 2016).

1.7.2 Effects of the Arachidonic Acid Pathway. Metabolites of the arachidonic acid pathway, specifically those derived from the cyclo-oxygenase (COX) reactions may also play a role in the tone of peripheral arterioles. Arachidonic acid is released by phospholipase A2 where it can be acted on by the COX enzymes to produce cycloendoperoxides which are then acted on by tissue specific enzymes (Weksler, 1981). Platelets are known to produces thromboxanes, whereas the endothelium produces prostacyclin and the vascular smooth muscle produces prostaglandins (Félétou, Huang, \& Vanhoutte, 2011). It is important to note that while prostaglandins and prostaclyclins are considered vasodilatory, thromboxanes are potent vasoconstrictors that are produced by aggregating platelets (Neppl et al., 2009). Platelet 
aggregation is known to occur in pulmonary injury models and is also important in the production of thrombospondin-1 (TSP-1), which has been shown to attenuate the actions of the endothelium after particulate matter inhalation (Mandler, Nurkiewicz, Porter, Kelley, \& Olfert, 2018a)

The arachidonic acid pathway is also important in immune responses, COX-2 activity is associated with inflammatory conditions and has been shown to suppress the activity of several immune cells (most notably T cells and NK cells) (Liu, Qu, \& Yan, 2015). The products of COX-2 may be responsible for alterations of vascular tone acutely and chronically may contribute to the dampened actions of the immune system in the lungs and airways of E-cigarette users.

\subsubsection{Effects of Thrombospondin-1 and its Receptor CD47. TSP-1 can be produced by}

most cells in the body, but is a major secretory product found in alpha-granules of aggregating platelets and secreted during pulmonary injury. Studies have shown that the TSP-1 receptor CD47 mediates can mediate its effects on the peripheral vasculature (Mandler, Nurkiewicz, Porter, Kelley, \& Olfert, 2018b). In the context of E-cigarettes, it is possible that particulate matter deposited in the lungs (Manigrasso, Buonanno, Stabile, Morawska, \& Avino, 2015) stimulates platelet aggregation and therefore TSP-1 secretion following acute exposure to Ecigarette vapor. In situations in which TSP-1 is chronically elevated it has been shown to stimulate vascular smooth muscle proliferation, inhibit endothelial cell proliferation and activate MMP enzymes which may also contribute to vascular dysfunction (Lawler, 2002). Currently there is no published data concerning acute E-cigarette exposure and the TSP-1/CD47 axis, however data indicating vascular dysfunction upon E-cigarette exposure (Anderson et al., 2016; Lehr, 2000) indicates further study into this mechanism is warranted. 
1.7.4 Effects of Endothelin-1. Endothelin-1 is another potentially important molecule in the E-cig induced vascular dysfunction mechanism. It is known that increased exposure to free radicals can upregulate endothelin-1 secretion by vascular endothelial cells, causing long lasting vasoconstriction (Houde, Desbiens, \& D’Orléans-Juste, 2016). Recent data suggests that a feedback between nitric oxide and endothelin-1 may be a major mechanism of myoendothelial coupling and therefore arteriolar diameter (Hilgers \& De Mey, 2009). Endothelin-1 transcription levels are the primary means of regulation of expression, edn-1 transcription (the gene that codes for endothelin-1) has been found to be upregulated in hypoxia (Stow, Jacobs, Wingo, \& Cain, 2011). This upregulation in expression has been shown to be inhibited by dilazep (Shrestha et al., 2004). In the context of E-cigarette use, it is possible that insult to the lungs may increase edn-1 transcription and therefore endothelin-1 levels, thereby causing systemic vasoconstriction, increased vascular smooth muscle cell proliferation and decreased endothelial cell proliferation. This mechanism may also play a role in decreased endothelial-dependent dilation with chronic exposure to E-cigarettes (Olfert et al., 2018).

This mechanism is of interest as expression of endothelin-1 has been shown to increase upon inhalation of particulate matter smaller than $2.5 \mu \mathrm{m}$ in diameter (Brook et al., 2002), and chronic elevation of endothelin-1 has been shown to be linked to increased rates of cardiovascular events (Brook et al., 2002). Recent data characterizing the particulate matter inhaled by E-cigarette users shows that average particulate diameter is between $250-450 \mathrm{~nm}$ (Ingebrethsen et al., 2012), within range to elicit the response of the endothelin-1 pathway. This mechanism is likely important in evaluating the long-term safety of E-cigarette use and further research is warranted to characterize the response. 
1.7.5 Effects of the Renin/Angiotensin System. In physiological conditions the reninangiotensin system plays a role in maintaining fluid balance, preventing dehydration and ion imbalances. In pathological conditions however, overactivation of the renin-angiotensin system has been shown to cause hypertension (Madhur et al., 2010), superoxide production (Jaimes, Galceran, \& Raij, 1998) and as an activator of NF-KB (Mezzano et al., 2001). These effects are caused by the product of the renin angiotensin pathway, angiotensin II. Banday et al. have shown that oxidative stress and the renin-angiotensin system can upregulate each other causing chronic hypertension and upregulation of inflammatory cytokines (Banday \& Lokhandwala, 2008).

The mechanism underlying how oxidative stress and angiotensin II induced hypertension is unclear. Data does, however, show that in situations in which angiotensin II is chronically elevated, the kidneys express higher levels of angiotensin II receptor, and therefore an exaggerated response to angiotensin II secretion is observed (Banday \& Lokhandwala, 2008). This response leads to an increase in sodium retention (Beltowski, Wójcicka, Marciniak, \& Jamroz, 2004) which is likely to further exacerbate the hypertension as well as contribute to oxidative stress.

Cigarette smoking has been shown to increase expression of angiotensin II as well as angiotensin converting enzyme in the lungs (Yuan et al., 2015). The effects of E-cigarettes in this context have yet to be evaluated but known increases in oxidative stress upon exposure to Ecigarette vapor and the likelihood of interplay with the renin-angiotensin system warrants further research. 


\subsubsection{Potential Sympathomimetic Effects of Vapor Constituents. Another potentially}

relevant mechanism of E-cigarettes effecting vascular tone is sympathomimetic effects of nicotine or other vapor constituents. While it is known that nicotine is sympathomimetic (Chiou, Trzeciakowski, \& Klein, 1976), there is no scientific consensus concerning the effects of other constituents of E-cigarette liquid on the autonomic nervous system. Human E-cigarette exposure studies by Moheimani et al. showed that heart rate variability during an exercise test (a measure of sympathetic activation) was only significantly elevated in subjects exposed to Ecigarette vapor containing nicotine (Moheimani et al., 2017). This means that while vascular tone may be altered by E-cigarettes through the other mechanisms listed above, sympathetic activation caused by nicotine may exacerbate these effects. Other constituents of E-cigarette vapor are not likely to alter tone through this mechanism, but further work is needed in this area to better understand what biological effects the individual components of E-cigarette vapor have toward health and disease. 
Chapter 2: Specific Aims 
Tobacco use is widely considered the single greatest risk factor for preventable disease and death in the developed world(Center for Disease Control and Prevention, 2011). Effects of tobacco smoke and nicotine, the main addictive component of tobacco, have been extensively characterized. Electronic cigarettes (E-cigarettes) are among the fastest growing tobacco products worldwide, especially among users aged 16-26 (Leventhal et al., 2015). E-cigs work by heating a mixture of propylene glycol, glycerin, flavoring and often nicotine with an atomizer and allowing the user to inhale the aerosol. It is not surprising that E-cigarettes are increasing popularity as marketing attempts to portray E-cigarettes as "safe" alternatives to cigarettes, however scientific and clinical evaluations about the acute and chronic effects from using Ecigarettes are still poorly understood.

Cigarette smoking has also been known to be linked to pathogenesis of cardiovascular disease (CVD) (Smoking \& Disease, 2018), this progression is known to occur through inflammatory mechanisms. CVD development is in part due to the toxicity of cigarette smoke to endothelial cells (Giunzioni et al., 2014; Lehr, 2000). While cell culture and ex vivo studies have demonstrated an inflammatory response of neutrophils (Reidel et al., 2010; Higham et al., 2016) and decreased aortic endothelial dependent relaxation (Olfert et al., 2018) in response to E-cig vapor, there is little data detailing the response of the vasculature to E-cigarette exposure in vivo.

The inflammatory response to cigarette smoke has been well characterized; the immune system mediates this response through the release of proinflammatory cytokines ("Cigarette smoke extract induced cytokine and chemokine," n.d.). Studies detailing the immune response to E-cigs have mostly focused on isolated cells. These studies have found a significant decrease 
in cellular antioxidant defenses and DNA damage (Ganapathy et al., 2017), increased rates of viral infection (Wu et al., 2014) and cell death in vascular endothelial cells (Anderson et al., 2016). The results of these studies indicate a need for further study on the effects of inflammatory cytokine expression in potentially vulnerable tissues.

Vascular tone is determined by the complex interaction of factors that cause vascular smooth muscle to contract or relax (Félétou et al., 2011; Neppl et al., 2009). Several factors can regulate vascular tone, including by altering the bioavailability of nitric oxide (Beckman \& Koppenol, 1996; Jeremy et al., 2002). The immune system is capable of causing oxidative stress on the endothelial cells that line the luminal surface of the vasculature and produce nitric oxide (Kuzkaya et al., 2003). Other vascular responses to particulate matter may cause acute alterations in vessel tone and may be chronically toxic to the cardiovascular system (Brook et al., 2002).

This study aims to address increase knowledge of how acute E-cigarette exposure alters peripheral vascular tone, and how chronic exposure may alter the expression of proinflammatory cytokines in potentially vulnerable tissues.

Specific Aim 1: Determine the in vivo effects of acute E-cigarette exposure on vascular tone in the gluteus maximus vasculature.

Our hypothesis is that E-cigarette exposure will decrease vessel diameter through decreased nitric oxide production or increased stimulation of vascular smooth muscle cells to increase vessel tone. 
Specific Aim2: Determine the effects of chronic E-cigarettes exposure on cytokine expression in various tissues.

Our hypothesis is that chronic E-cigarette exposure increases the concentration of proinflammatory cytokines. 
Chapter 3: Methods 
C57BL/6 mice were used for all experiments (Jackson Laboratories, Bar Harbor ME.).

Mice were housed in a temperature and humidity-controlled vivarium with a 12-hour light/dark cycle and ad libitum access to standard rodent diet chow and tap water. All experiments were approved by and conducted in accordance with the guidelines of the West Virginia University Institutional Animal Care and Use Committee.

\subsection{Intravital surgery prep}

Mice were anesthetized with intraperitoneal injections of Thiobutabarbital (Inactin, 100 $\mathrm{mg} / \mathrm{kg}$ ) using a $1 \mathrm{ml}$ syringe and a 27-gauge needle. Anesthesia was administered via 3 doses with approximately 20 minutes between doses. Assessment of adequate anesthesia was performed by toe pinch. During anesthesia period a heat lamp was used to prevent hypothermia.

After anesthesia was determined to be adequate an endotracheal tube (polyethylene PE90 tubing approximately an inch long) was inserted via tracheostomy and secured with suture (Figure 3.1A). The incision made during tracheostomy was sutured shut to prevent insensible fluid loss and to further secure the endotracheal tube in place. Endotracheal tube was trimmed to below chin length to mimic anatomical dead space

After successful placement of the endotracheal tube an incision just lateral to the dorsal midline (Figure 3.1B) was made to visualize the gluteus maximus tendon, the gluteus muscle was then exposed by further incisions to the skin around the hindlimb. After the gluteus maximus muscle was exposed it was kept moist with normal saline applied as needed throughout the prep. Vannas scissors were used to make an incision into the gluteus tendon 

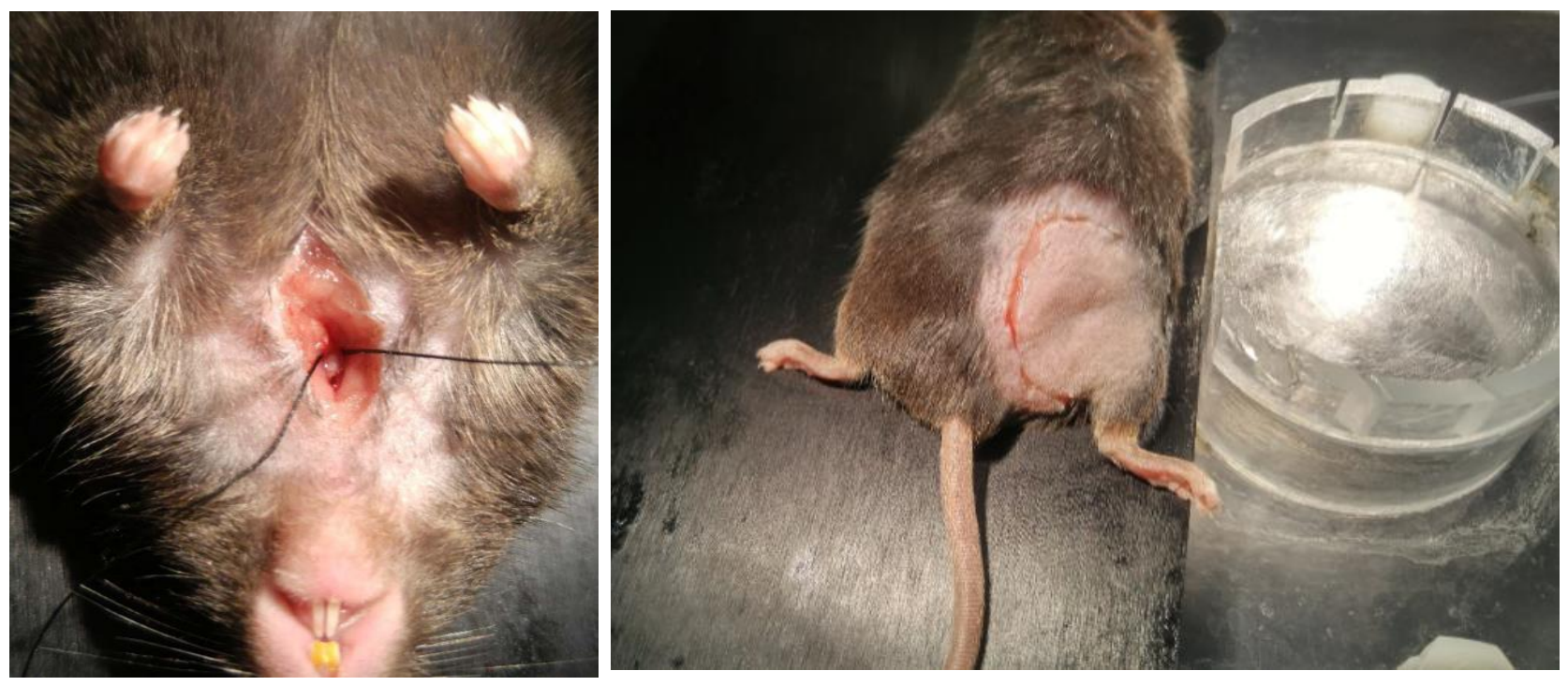

Figure 3.1 Legend: A) Tracheostomy in an anesthetized mouse, B) Incision site for exteriorization of the gluteus maximus muscle for IVM procedure. Images courtesy of W. Kyle Mandler, PhD.

and the gluteus maximus was separated from the gluteus medius by spreading the two apart with the blunt edges of the vannas blades.

Further incisions to the gluteus maximus muscle were used to visualize the vasculature within the muscle, after a sufficient portion of the muscle was trimmed away from the tendon a suture was tied using a double loop to prevent tying from clamping the muscle (Figure 3.2). Traction was applied to the muscle and then the superior and inferior edges of the muscle were trimmed away using the traction to facilitate separating the gluteus maximus from the gluteus medius (Figure 3.2). Avoiding damage to the neurovascular plexuses on the superior and inferior edges of the muscle is imperative as cutting those vessels may result in the death of the animal. 
Superior and inferior sutures were tied in the same manner as the first tie and the muscle was then incubated in a heated bath of physiological saline solution that was sealed with stopcock grease. Compressed gas ( $5 \%$ carbon dioxide, balance nitrogen) was bubbled through the physiological saline to more closely mimic the interstitial fluid. Heart rate, body temperature and bath temperature were monitored throughout, and additional anesthesia was given when necessary.

A water immersion microscope was used to visualize a second-order arteriole in the exposed gluteus maximus. A heated stage was used to maintain body temperature, which was monitored and automatically regulated using rectal probe. Fluid was replenished in the bath at

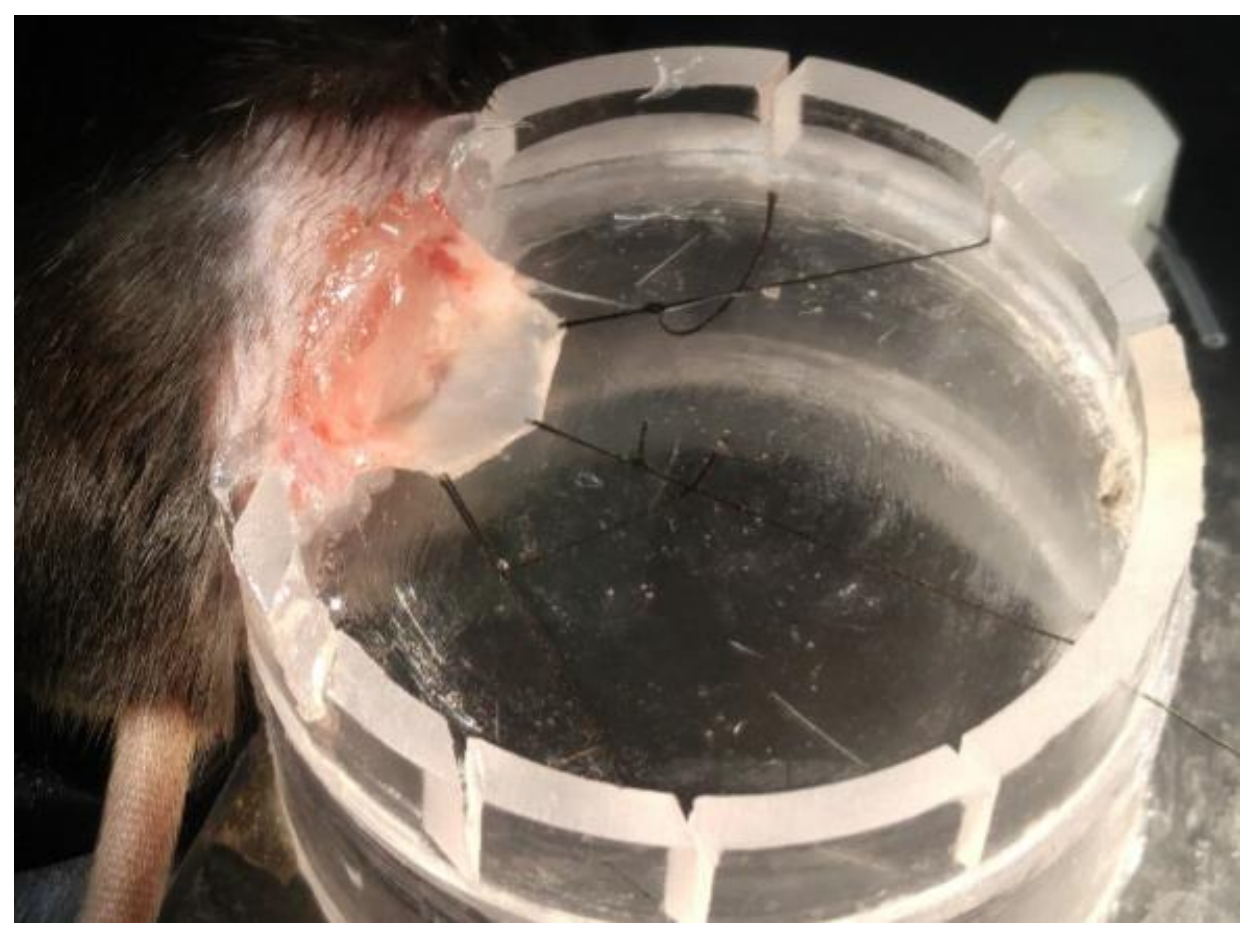

Figure 3.2. Approximately $1 \mathrm{~cm}$ Externalized portion of the gluteus maximus muscle in an anesthetized mouse. Submerged in a $4.5 \mathrm{~cm}$ diameter physiological saline solution bath. Note the double loop knot in the suture preventing the suture from applying pressure to the muscle. Image courtesy of W. Kyle Mandler, PhD. 
a rate of $4 \mathrm{ml} / \mathrm{min}$ to maintain fresh bath environment and temperature. Two separate series of were performed, 1) two-hour time course evaluation, and 2) shorter (50-min) time course which included vascular reactivity assessments to varying vasodilation (i.e. acytelcholine) stimulation.

3.1.1. Intravital Study 1: The first invtravital experiments were to determine the effects of acute E-cigarette exposure on the peripheral vasculature mice for the longest time possible ( 2hours) while anesthetized under intravital microscopy. A baseline image of the vessel was taken for comparison post exposure. Before exposure, vasodilatory response to $1 \times 10^{-3}$ molar acetylcholine was also performed by adding the drug to the bath and incubating for 5 minutes. Acetylcholine was washed out and vessels returned to baseline before exposure occurred. Thereafter, the animal was exposed to vapor for 5 minutes ( 5 second puffs, $55 \mathrm{ml}$ puff volume, 30 seconds apart for a total of 10 puffs), or to the smoke of one 3R4F reference cigarette (Univ. of Kentucky). Mice were exposed to commercially available French vanilla flavored E-cigarette vapor (containing either 0 or $18 \mathrm{mg} / \mathrm{ml}$ of nicotine) (VG/PG-0 and VG/PG-18, respectively), 3R4F reference cigarette, $100 \%$ vegetable glycerin (no nicotine) (VG-0), or $100 \%$ propylene glycol (no nicotine) (PG-0) using a rodent ventilator and tubing to deliver to the smoke/vapor to the endotracheal tube. An untreated (sham) group underwent the same intravital prep but was not exposed to any smoke or vapor treatment.

After exposure, images of the vasculature were taken in 15-minute intervals for up to 120 minutes (or until the animal died). These images were then measured using ImageJ software (NIH), scale was set using measurements from a micrometer and was equal to 300 
pixels $=100 u M$. Data was plotted in terms of both absolute vessel diameter and percent change from baseline.

3.1.2. Intravital Study 2. A second series of studies were conducted to obtain better time resolution of acute vascular response within 1-hour of exposure and to determine if the endothelium-dependent dilation capacity of second-order arterioles was impaired by acute exposure to E-cigarette vapor. After baseline was assessed, a 3-point acetylcholine dilation curve was obtained $\left(10^{-7}, 10^{-5}\right.$ and $\left.10^{-3} \mathrm{M} \mathrm{ACh}\right)$. Acetylcholine was placed in the bath for 5minute intervals with images taken at the end of each interval.

After the end of the first acetylcholine curve animals were exposed VG/PG-0, VG/PG-18 3R4F reference cigarette, or PG-0 using a rodent ventilator and tubing to deliver to the smoke/vapor to the endotracheal tube. Images of the vessel were taken in 10-minute intervals for 50 minutes

After the 50-minute incubation, a second identical acetylcholine dose response curve was obtained. Dilatory capacity was assessed by measuring vessel diameter with ImageJ calibrated to measurements from a micrometer. Data was plotted in terms of absolute diameter and percent change from baseline. A timeline of the second surgical series is provided below for the sake of clarity (Figure 3.3). 


\section{Timeline of Study 2 Experiments}

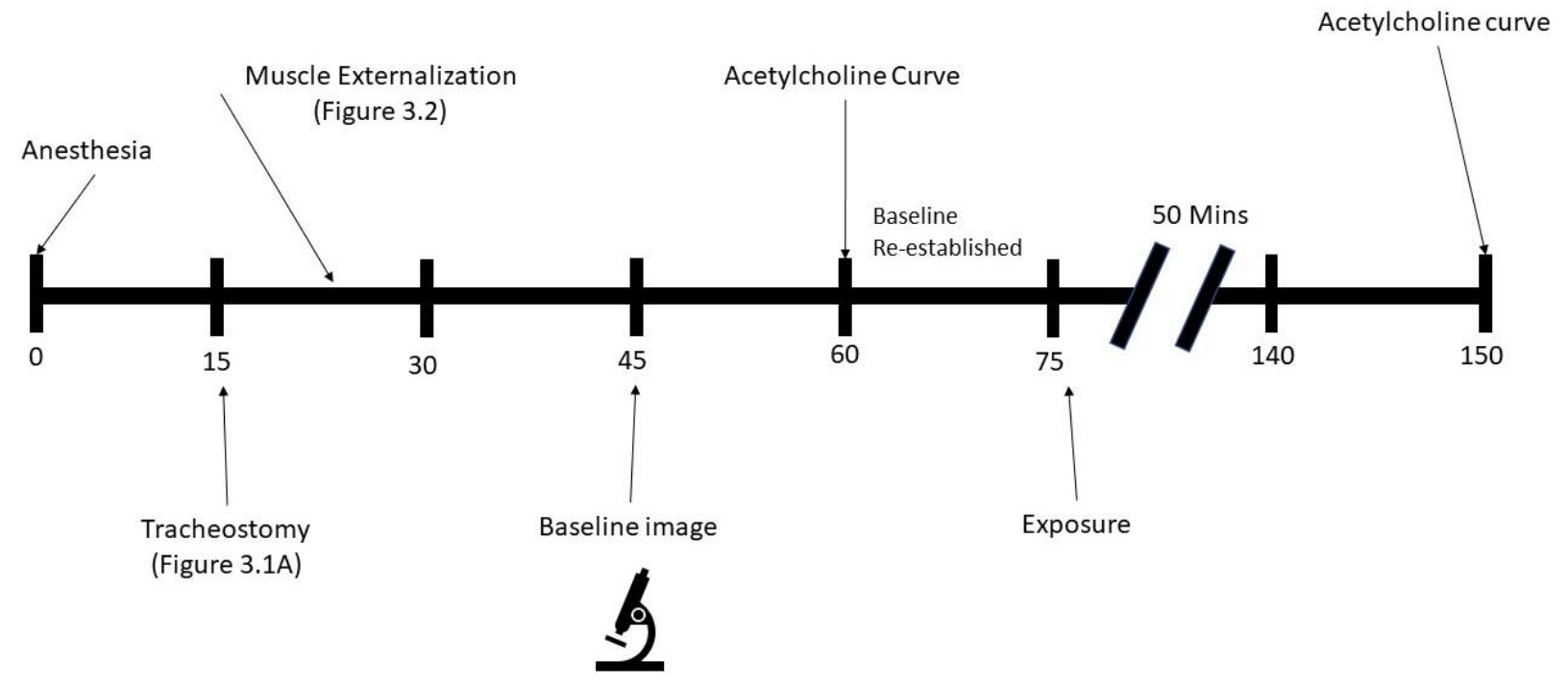

Figure 3.3 Timeline in minutes showing order of procedures in Study 2. 0 minutes represents time at which animal was determined to be adequately anesthetized for the procedure. Microscope icon represents the time at which the animal was placed under microscope and externalize portion of muscle was placed in the physiological saline bath.

\section{Cytokine Analysis Experiments.}

Ten-week old female C57BL6/J mice ( $n=45$, purchased from Jackson laboratory, Bar Harbor, ME Stock \#000664) and randomly assigned to be exposed to either 3R4F reference cigarette (University of Kentucky, http://www.ca.eky.edu/refcig), commercially available cappuccino flavored E-cigarette vapor $(18 \mathrm{mg} / \mathrm{ml}$ of nicotine $50 \%$ propylene glycol:50\% vegetable glycerin base liquid ratio) or compressed room air ( $n=15$ per group). Mice were acclimatized to the new facilities for one week before start of exposures, and group housed by treatment (E-cigarette exposed mice were only housed with other E-cigarette exposed mice, etc.). Facility conditions were kept constant throughout the exposure period and included a 12$\mathrm{h}$ light/dark cycle, $22 \pm 4^{\circ} \mathrm{C}$ temperature, and $39 \pm 6 \%$ relative humidity. Mice were given access 
to ad libitum tap water and standard rodent chow (18\% fat, 24\% protein, 58\% CHO; Teklad Diet, Madison, WI). Cage bedding was changed on a bi-weekly basis and injuries (as a result of fighting, etc.) were treated upon consultation of vet staff.

Mice exposed to E-cigarette vapor and cigarette smoke were exposed using separate, but identical 15.1-liter whole body exposure chambers. Vapor and smoke were generated using separate but identical small animal ventilators (HARVARD APPARATUS Dual Phase Control Respirator, Model 55-0715, South Natick, Massachusetts). Vapor was generated using a custom-built E-cigarette cradle (SONGLE, Dr. Powsiri Klinkhachorn, Dept. of Electrical Engineering, West Virginia University, Morgantown, WV) that allowed for precise 5-second puffs every 99 seconds (for a total of 38-39 puffs per hour) and a commercially available "tank

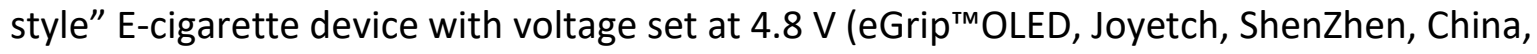
www.joyetch.com). Smoke was generated by inserting and lighting one cigarette every 10 minutes into the ventilator ( 6 cigarettes per hour). Animals were acclimatized to the smoking protocols by smoking 1 hour per day the first week of exposure, then adding an hour per day each week until 4 hours per day was reached.

After the acclimatization period, animals were exposed simultaneously in separate chambers for 4 hours per day 5 days per week for a total of 8 months. At the end of the 8 month exposure period animals were given 24 hours of no exposure and fasted for 8 hours. Animals were then anesthetized with intraperitoneal ketamine/xylazine. Blood was collected from a left ventricular puncture and flash frozen then stored at $-80^{\circ} \mathrm{C}$ for later analysis. Other major organs including brain, lung, and gastrocnemius muscle were dissected and flash frozen the stored at $-80^{\circ} \mathrm{C}$. Bronchoalveolar lavage was also performed and fluid was saved, flash 
frozen and stored at $-80^{\circ} \mathrm{C}$. Homogenates of brain, lung and gastrocnemius were made using a tris-based buffer. A Meso-Scale Discovery (MSD) U-plex kit (Meso-Scale Discovery Rockville, Maryland) was run according to manufacturer's instructions (cytokines tested included: VEGF, IL-4, IL-5, IL-6, IL1B, IL-15, IL-10, interferon-gamma, granulocyte-macrophage colony stimulating factor and TNF- $\alpha$ ). Results are shown below.

Statistical Analyses

Repeated measures ( $\mathrm{rANOVA}$ ) was used when more than one measurement of the same variable was obtained in the same animal. If a significant main effect for either exposure or time was found using rANOVA, Students t-test was used to determine differences by time point or between groups. In cases of single measurements, ANOVA was used to determine significant main effects between exposure groups, and if a main effect was observed Fisher's post-hoc testing was used to determine significance between groups. 
Chapter 4: Results 


\section{Study 1: 2-hour time course}

Shown in Table 1 are body mass, age of the mice at sacrifice in each respective group and sex of animals used in this study.

\begin{tabular}{|l|l|l|l|}
\hline & Body Mass & Age & Sex (\% Male) \\
\hline Sham & $22.0 \pm 1.7 \mathrm{~g}$ & $90 \pm 11$ days & $33 \%$ \\
\hline E-Cig & $22.0 \pm 0.8 \mathrm{~g}$ & $89 \pm 3$ days & $42 \%$ \\
\hline 3R4F & $23.5 \pm 0.5 \mathrm{~g}$ & $85 \pm 1$ days & $100 \%$ \\
\hline
\end{tabular}

Data are presented as mean \pm standard error.

Blood vessel diameter was monitored using intravital microscopy for up to 2 hours after exposures. Vessel responses are plotted in terms of absolute diameter, and as a percentage of pre-exposure diameter (baseline). Repeated-measures ANOVA show that E-cigarette vapor (independent of nicotine content) and 3R4F reference cigarettes shows similar decrease in diameter over time (rANOVA $\mathrm{P}<0.05$ for absolute diameter and rANOVA $\mathrm{p}<0.01$ for diameter with respect to baseline) with both significantly different from sham control groups (Figure 4.1).

Further investigation using the 2-hour time course paradigm showed that VG/PG-0, VG/PG-18PG-0, VG-0 and 3R4F reference cigarette also yield similar changes over time. Data were plotted as vessel diameters and with respect to baseline and rANOVA yielded statistically significant treatment $x$ time interactions in both cases $(P<0.05$ for both). These results are shown in Figure 4.2

There were significant differences in male and female animals' body weights (ANOVA $P<0.05)$ and baseline vessel diameter $(P<0.05)$. There was not however, a significant sex by time 
interaction, or significant differences in clinical data such as heart rate, body temperature or bath temperature ( $P=N$.S. for all). 
Study 1: Two-hour Time Course

Tobacco cigarette (3R4F) vs. Electronic Cigarette
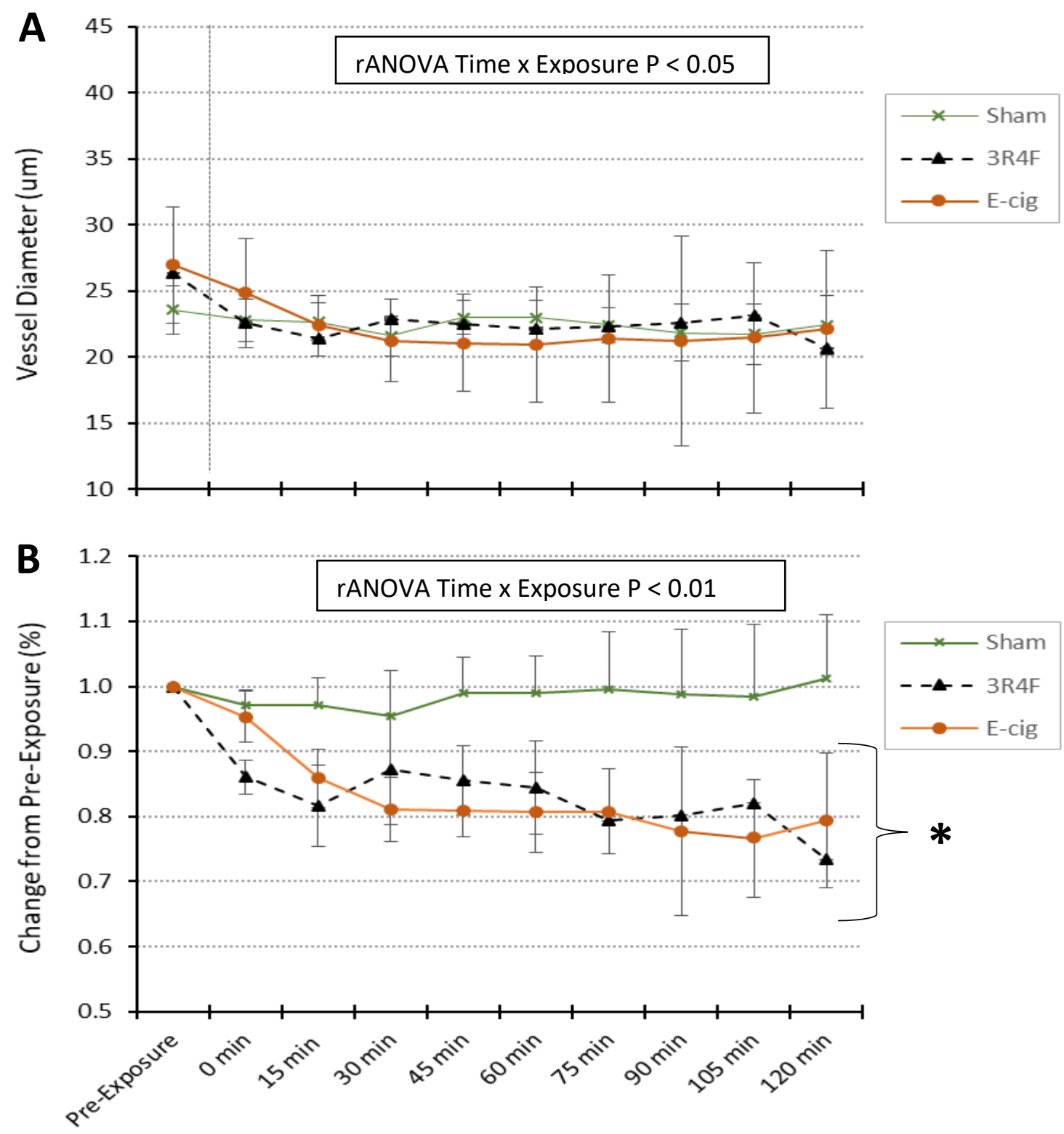

Figure 4.1 Time course assessment of 2 nd order arteriole vessel diameter in the gluteus maximus muscle measured under intravital microscopy before and up to 120-minutes post exposure to traditional tobacco cigarettes (3R4F) versus an electronic cigarette. Vessel diameters are shown in top panel, and responses normalized to pre-exposure basal diameters (set to 1.0) are shown in bottom panel. Dotted indicates when 5-minute exposure occurred. Number of animals in each group is as follows: Sham ( $n=5), 3 R 4 F(n=2)$, E-cig $(n=19)$. 

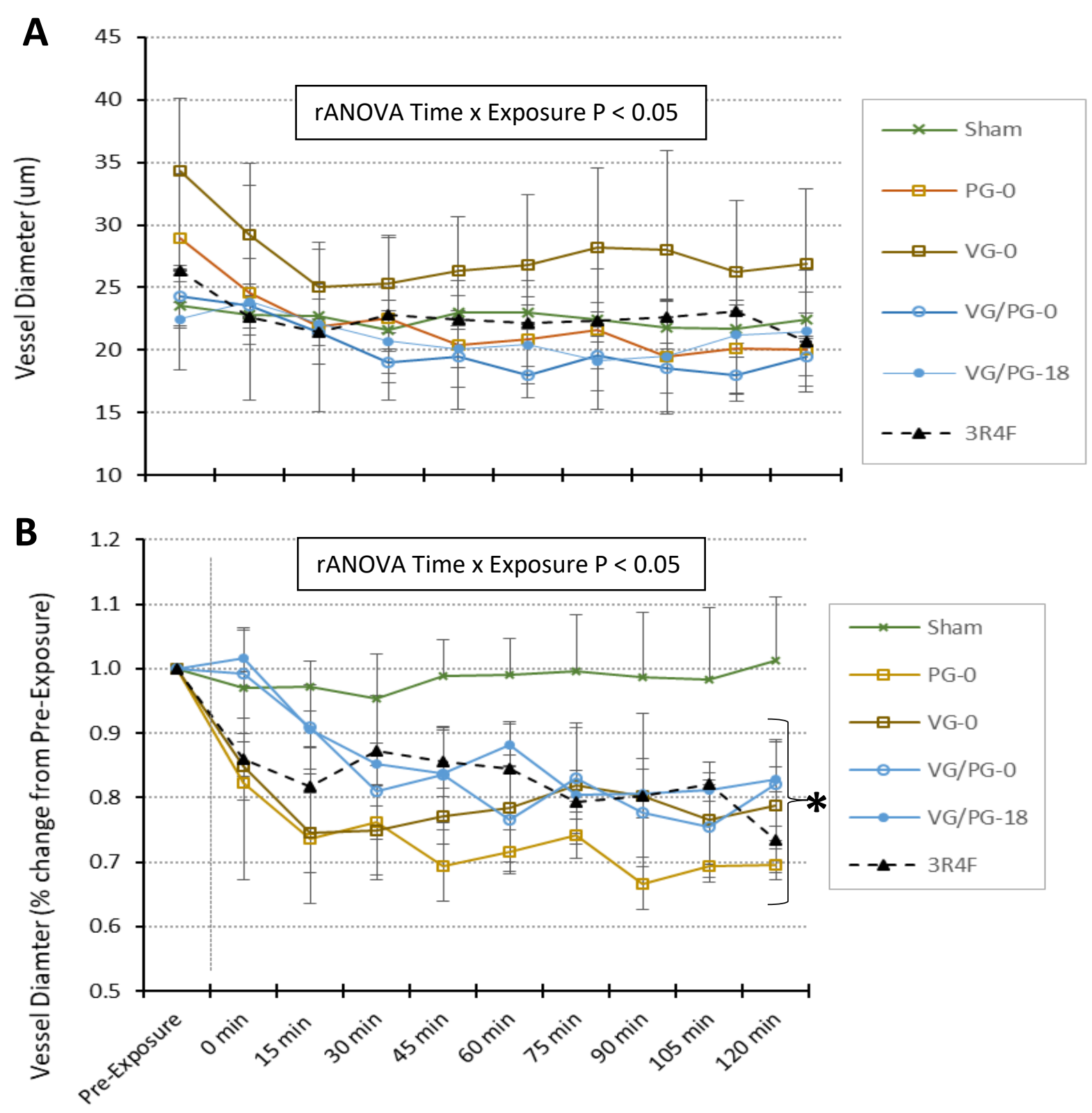

Figure 4.2 Time course assessment of 2 nd order arteriole vessel diameter in the gluteus maximus muscle measured under intravital microscopy before and up to 120-minutes post exposure electronic cigarettes using different e-liquid composition and nicotine (i.e., PG-0, 100\% propylene glycol with $0 \mathrm{mg}$ nicotine; VG/PG-0, 50\% vegetable glycerin:50\% PG with $0 \mathrm{mg}$ nicotine; VG/PG-18, 50:50 VG/PG with $18 \mathrm{mg} / \mathrm{ml}$ nicotine). Vessel diameters are shown in top panel, and responses normalized to pre-exposure basal diameters (set to 1.0) are shown in bottom panel. Tobacco cigarette (3R4F) shown for reference. Dotted indicates when 5-minute exposure occurred. Numbers of animals in each group were as follows Sham $(n=5), P G-0(n=3)$, VG-0 (n=3), VG/PG-0 (n=5), VG/PG-18 $(n=8)$ and 3R4F $(n=2)$. 
Study 1: Two-hour Time Course
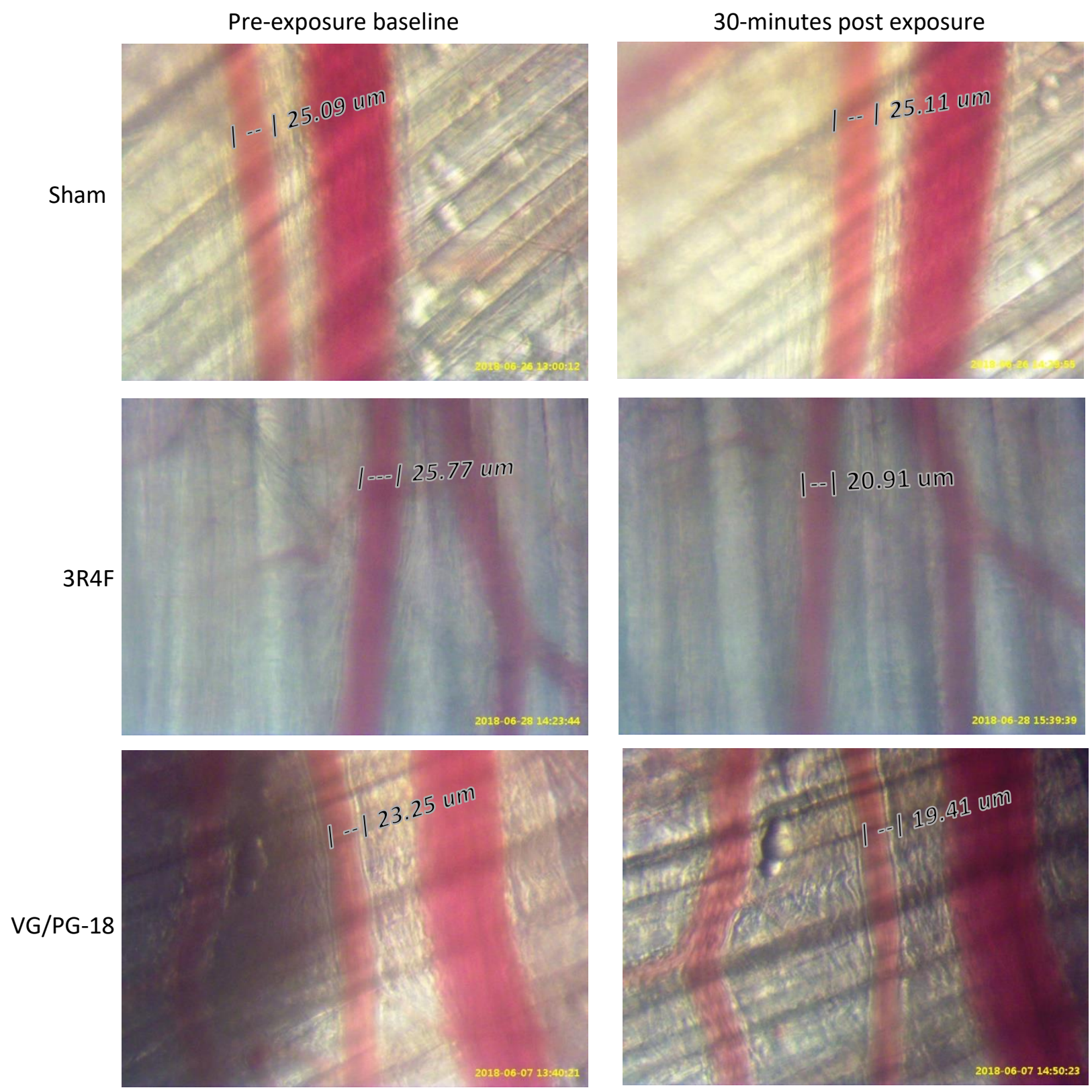

Figure 4.3 shows the response of second order arterioles to inhalation exposures in the gluteus maximus muscle of mice. Pictures on the left are pre-exposure baseline images and pictures on the right are the same vessels 30 minutes after exposure. Average diameter (from 3 measurements) is shown on the image. 


\section{Study 2: Vascular Reactivity after 50-Minutes following Vaping}

Shown in Table 2, are body mass, age at time of sacrifice, and sex of animals used in this study.

\begin{tabular}{|l|l|l|l|}
\hline & Weight & Age & \% male \\
\hline Sham & $24.3 \pm .7 \mathrm{~g}$ & $84 \pm 2$ days & 100 \\
\hline 3R4F & $25.5 \pm .6 \mathrm{~g}$ & $101 \pm 5$ days & 100 \\
\hline PG-0 & $22.8 \pm 1.3 \mathrm{~g}$ & $102 \pm 1$ days & 50 \\
\hline VG/PG & $25.6 \pm .3 \mathrm{~g}$ & $97 \pm 3$ days & 100 \\
\hline
\end{tabular}

Data presented as mean \pm standard error

Vessel diameters were plotted in terms of absolute vessel diameter and as a percentage of baseline. rANOVA analysis showed a tendency for time $x$ exposure interaction in absolute diameter analysis $(P=0.10)$ and a statistically significant time $x$ exposure interaction with respect to baseline $(P<0.05)$. These data are presented graphically in Figure 4.3.

Vascular reactivity assessment showed no significant impairment in endotheliumdependent dilation with exposure to 3R4F reference cigarettes (Figure 4.4 A and B). The slopes of dilation curves after exposure to 3R4F cigarettes were also not statistically significantly different. No significant endothelial impairment was observed with VG/PG-0 orPG-0. However, VG/PG-18 was found to have a greater slope after exposure (ANOVA P<0.05; Figure 4.4).

Analysis of heart rate, by comparing minimum and maximum recorded values, showed no statistical difference between groups. Body temperature analysis also showed no statistical differences between groups. Bath temperature delta value (maximum minus minimum) analysis shows a statistically significant increase in bath temperature variance (ANOVA P<0.05).

Principally due to greater pre-exposure differences in bath temp in VG/PG groups. Animals 
exposed to E-cigarette vapor (VG/VG) experienced an average bath temperature delta value of $2.6 \pm .4{ }^{\circ} \mathrm{C}$, compared to $1.7 \pm 0.2$ in animals exposed to $\mathrm{PG}-0,0.9 \pm 0.4$ in animals exposed to $3 R 4 F$ reference cigarettes and $1.0 \pm 0.2$ in sham animals (figure 4.5 ).

There were significant differences between male and female animals' vessel diameters and body weights (ANOVA $\mathrm{P}<0.05$ for both). But there were no sex $\mathrm{x}$ time interactions in terms of vessel response. There were also no significant differences in clinical variables such as heart rate, body temperature or bath temperature ( $\mathrm{P}=$ N.S. for both). 


\section{Study 2: 50-min Time Course}

\section{Electronic Cigarette using different E-liquids}

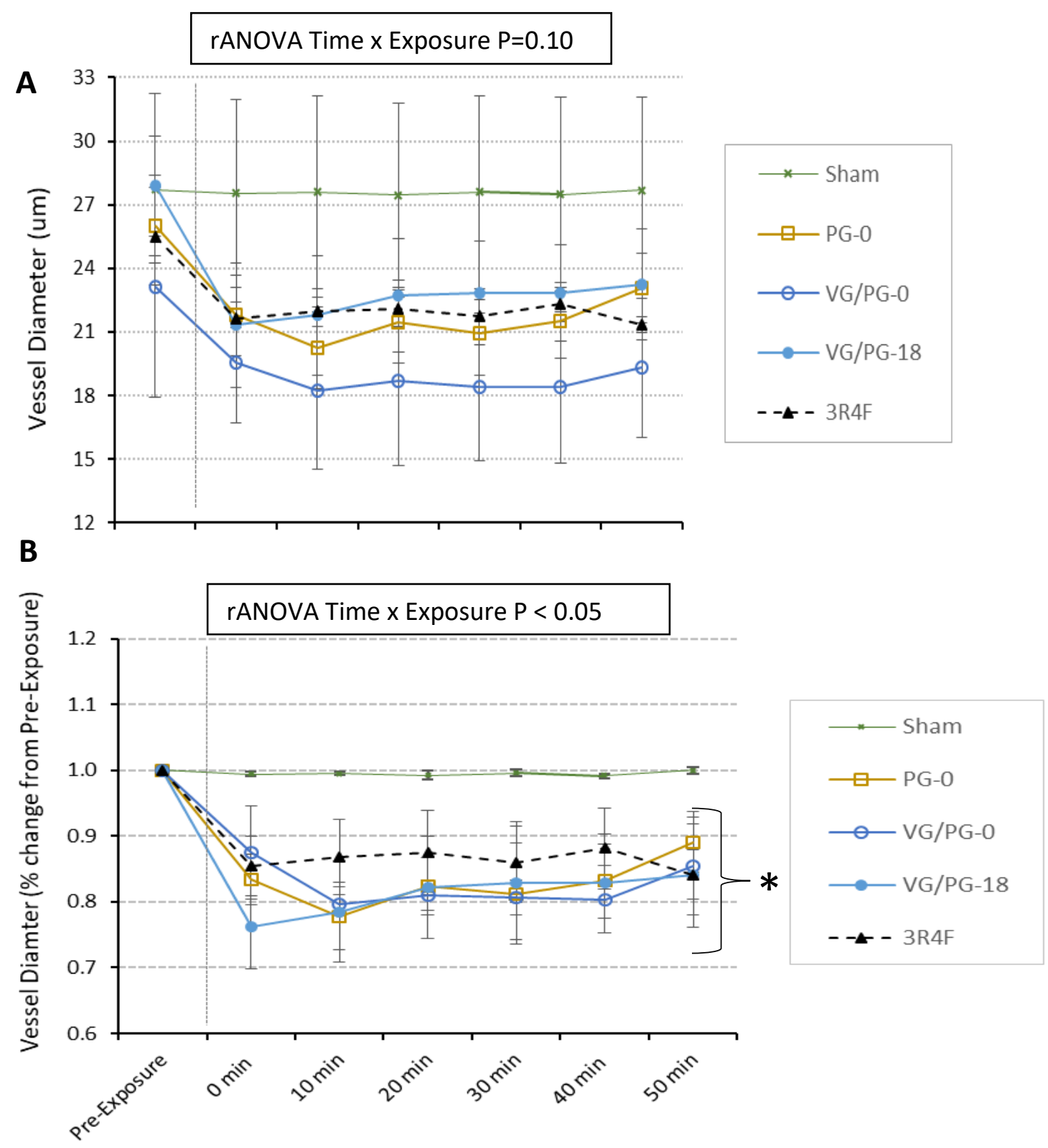

Figure 4.3 Basal diameters of second-order arterioles in the gluteus maximus muscle before and up to 50-minutes post exposure to tobacco cigarettes (3R4F) and E-cigarette using different e-liquid composition and nicotine (i.e., PG-0, 100\% propylene glycol with 0mg nicotine; VG/PG0, 50\% vegetable glycerin:50\% PG with 0mg nicotine; VG/PG-18, 50:50 VG/PG with $18 \mathrm{mg} / \mathrm{ml}$ nicotine). Absolute vessel diameters (top) and normalized diameters to pre-exposure (bottom panel). Dotted line indicates when 5-minute exposure occurred. Numbers of animals in each group were as follows: Sham ( $n=3)$, PG-0 $(n=6)$, VG/PG-0 $(n=3)$, VG/PG-18 $(n=4)$ and 3R4F $(n=5)$. 


\section{Study 2: Vascular Reactivity to Acetylcholine (ACh)}

Traditional Cigarette (3R4F)
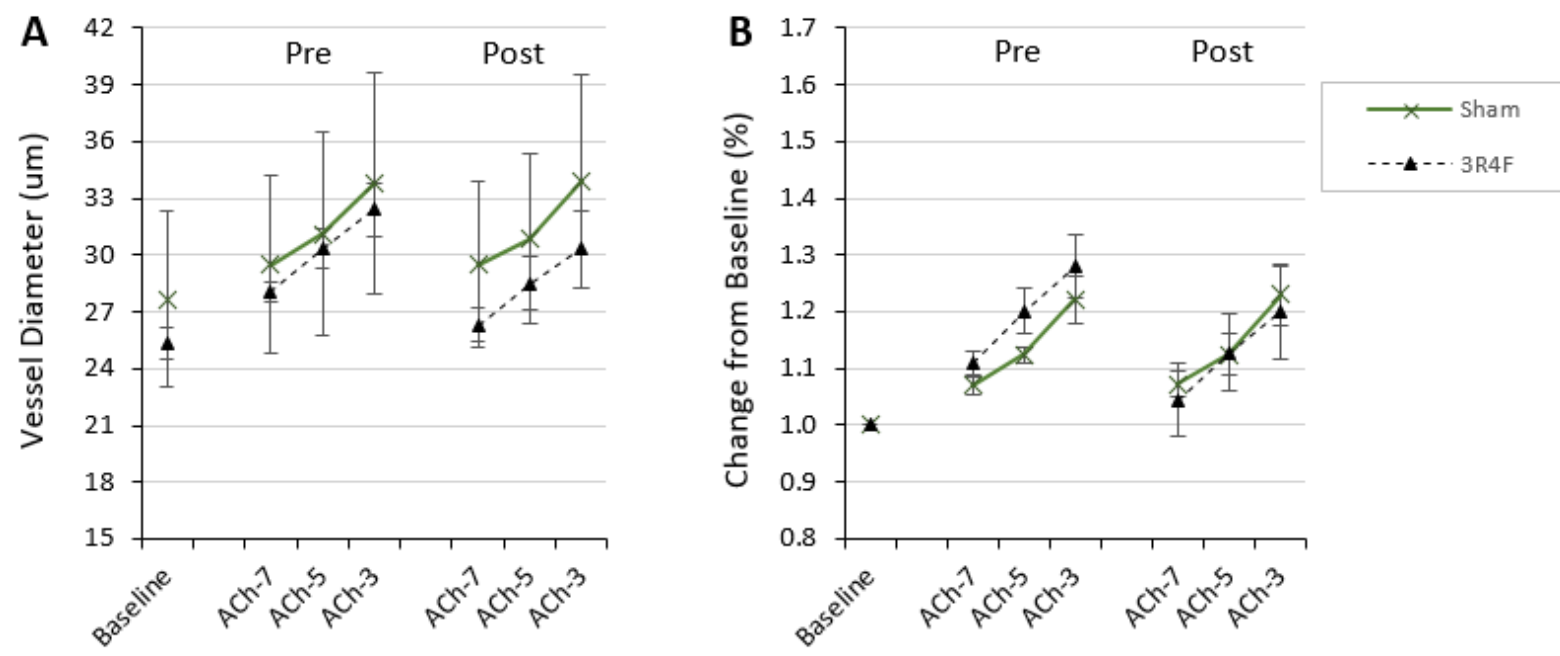

\section{Electronic Cigarette}
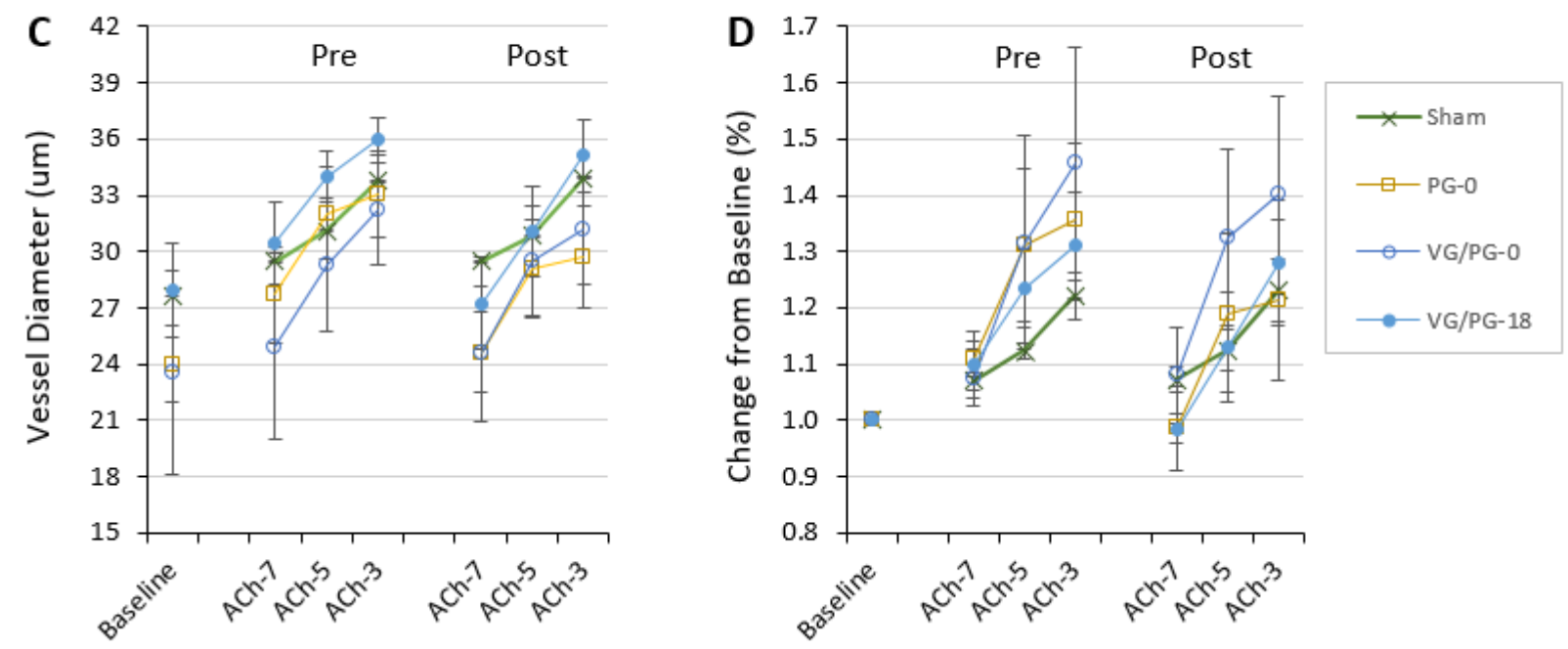

Figure 4.4 Vascular reactivity to increasing acetylcholine ( $A C h$ ) concentration of Pre and 1-hour Post exposure to traditional tobacco cigarette (3R4F, shown in A and B) and electronic cigarettes (shown in $\mathrm{C}$ and $\mathrm{D}$ ) with differing e-liquid composition and nicotine (i.e., PG-0, 100\% propylene glycol with $0 \mathrm{mg}$ nicotine; VG/PG-0, 50\% vegetable glycerin:50\% PG with $0 \mathrm{mg}$ nicotine; VG/PG-18, 50:50 VG/PG with $18 \mathrm{mg} / \mathrm{ml}$ nicotine). A \& C show vessel diameters obtained from 2 nd order arterioles in the gluteus maximus muscle under intravital microscopy. $B$ \& D show responses normalized to baseline diameters (set to 1.0). Numbers of animals in each group were as follows: Sham ( $n=3)$, PG-0 $(n=6)$, VG/PG-0 $(n=3)$, VG/PG-18 $(n=4)$ and 3R4F $(n=5)$. 

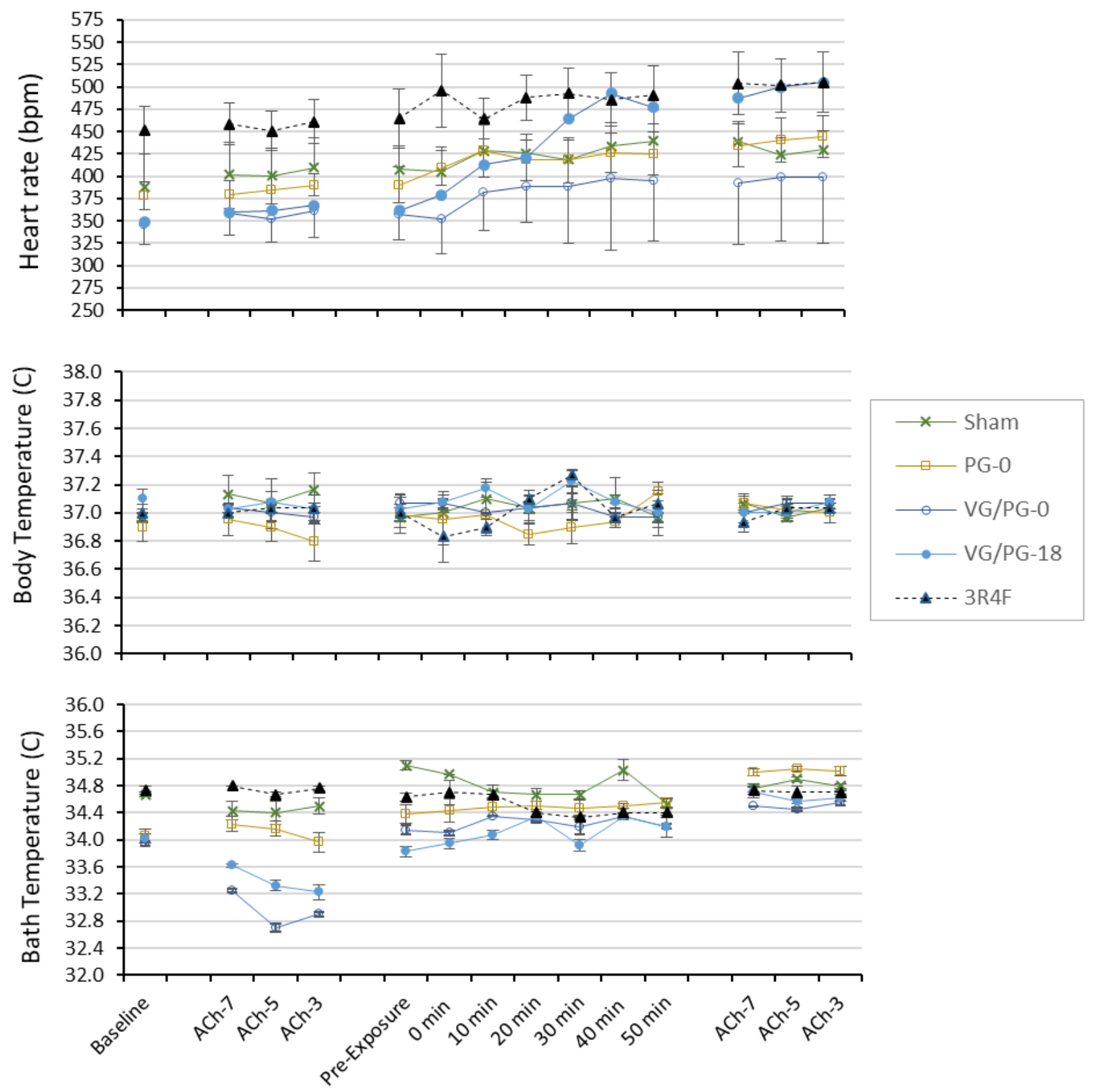

Figure 4.5 Heart rate (top), body temperature (middle) and intravital bath temperature (bottom) measurements obtained during Study 2 data collection. PG-0, 100\% propylene glycol with $0 \mathrm{mg}$ nicotine; VG/PG-0, 50\% vegetable glycerin:50\% PG with 0 mg nicotine; VG/PG-18, 50:50 VG/PG with $18 \mathrm{mg} / \mathrm{ml}$ nicotine; C, degrees Celsius. Numbers of animals in each group were as follows: Sham ( $n=3)$, PG-0 $(n=6)$, VG/PG-0 $(n=3)$, VG/PG-18 $(n=4)$ and 3R4F $(n=5)$. 


\section{Study 3: Chronic Exposure and cytokine analysis}

After cytokine assays were run, ANOVA was used to determine if statistical significance existed between groups. The P-values of each ANOVA are shown in Table 4.1. Statistically significant changes and tendencies were plotted in Figure 4.6. IL-6 content in the serum of groups was found to be statistically significant $(P<0.05)$ with air exposed animals expressing $3.535 \pm 0.917 \mathrm{pg} / \mathrm{ml}, 3 R 4 \mathrm{~F}$ exposed animals expressing $0.926 \pm 0.273 \mathrm{pg} / \mathrm{ml}$ and E-cigarette exposed animals expressing $1.503 \pm 0.658 \mathrm{pg} / \mathrm{ml}$. Analysis of VEGF and GM-CSF contained data from 6 animals per group IL- 6 analysis in the serum contained data from 8 air exposed animals, 7 3R4F exposed animals and 9 E-cigarette exposed animals.

While not statistically significant, VEGF content tended to be different in the lungs (ANOVA $P=0.059$ ) with air exposed animals expressing $8.266 \pm 0.866 \mathrm{pg} / \mathrm{ml}$, 3R4F exposed animals expressing $7.966 \pm 1.366 \mathrm{pg} / \mathrm{ml}$ and E-cigarette exposed animals expressing $4.455 \pm$ $1.156 \mathrm{pg} / \mathrm{ml}$. Bronchoalveolar lavage fluid (BALF) also tended to be different among groups (ANOVA $\mathrm{P}=0.06$ ) with air exposed animals expressing $0.418 \pm 0.066 \mathrm{pg} / \mathrm{ml}, 3 \mathrm{R} 4 \mathrm{~F}$ exposed animals expressing $0.563 \pm 0.062 \mathrm{pg} / \mathrm{ml}$, and E-cigarette exposed animals expressing $0.07 \pm 0.0$ $\mathrm{pg} / \mathrm{ml}$. GM-CSF expression in the lungs tended to be different between groups with air exposed animals expressing $0.07 \pm 0.01 \mathrm{pg} / \mathrm{ml}$, 3R4F exposed animals expressing $0.13 \pm 0.04 \mathrm{pg} / \mathrm{ml}$ and Ecigarette exposed animals expressing $0.04 \pm 0.01 \mathrm{pg} / \mathrm{ml}$. These results are presented graphically in Figure 4.6. 
Study 3: Chronic exposure to E-Cigarette Vapor

ANOVA Exposure Effect P-values for All Cytokines

\begin{tabular}{|l|c|c|c|c|}
\hline & $\underline{\text { Lung }}$ & $\underline{\text { Gastrocnemius }}$ & $\underline{\text { Serum }}$ & $\underline{\text { BALF }}$ \\
\hline VEGF & $\mathbf{0 . 0 5 9}$ & 0.470 & 0.934 & $\mathbf{0 . 0 6 0}$ \\
\hline TNF-a & 0.281 & 0.666 & 0.450 & 0.986 \\
\hline GM-CSF & $\mathbf{0 . 0 5 6}$ & 0.648 & 0.446 & 0.096 \\
\hline IFN-gamma & 0.662 & 0.383 & 0.625 & ISD \\
\hline IL-1B & 0.901 & 0.405 & 0.347 & 0.226 \\
\hline IL-4 & 0.910 & 0.181 & ISD & ISD \\
\hline IL-5 & 0.519 & 0.484 & 0.930 & 0.331 \\
\hline IL-6 & 0.543 & ISD & $\mathbf{0 . 0 4 0}$ & ISD \\
\hline IL-10 & 0.150 & 0.101 & 0.253 & 0.192 \\
\hline IL-15 & 0.210 & 0.698 & 0.714 & ISD \\
\hline
\end{tabular}

Table 3 shows P-values of ANOVA analysis of cytokine expression in tissues of Mice chronically exposed to either $3 \mathrm{R} 4 \mathrm{~F}$ reference cigarette, commercially available Cappuccinoflavored E-liquid (Joyetech, ShenZhen, China) $(18 \mathrm{mg} / \mathrm{ml}$ nicotine) or filtered room air. Bold values showed either tendencies $(P<0.06)$ or statistically significant $(P<0.05)$ changes in cytokine levels. Cells labelled ISD had insufficient data for ANOVA analysis. Cytokines tested were: vascular endothelial growth factor (VEGF), tumor necrosis factor- alpha (TNF-a), granulocyte-macrophage colony stimulating factor (GM-CSF), interferon-gamma (IFNgamma) and interleukins (IL) 1B, 4, 5, 6, 10, and 15. 
Lung VEGF Expression

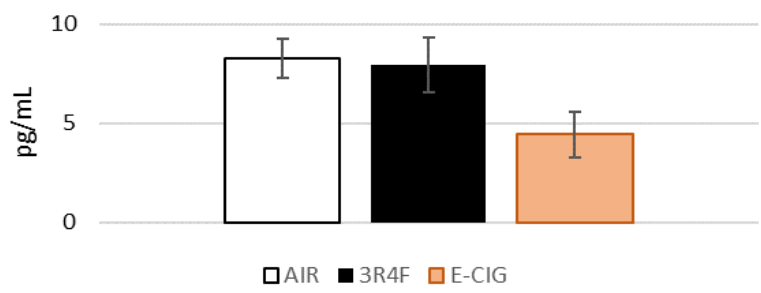

BALF VEGF Expression

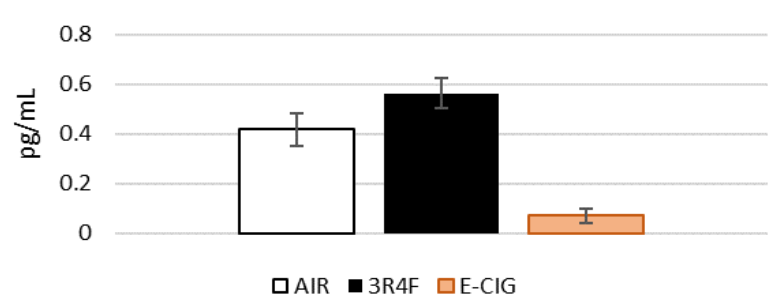

Lung GM-CSF Expression

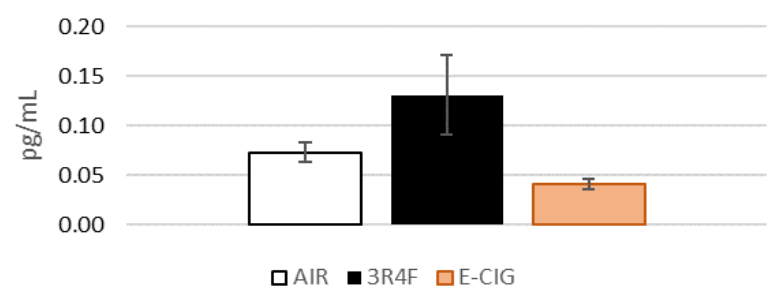

Serum IL-6 Expression

6

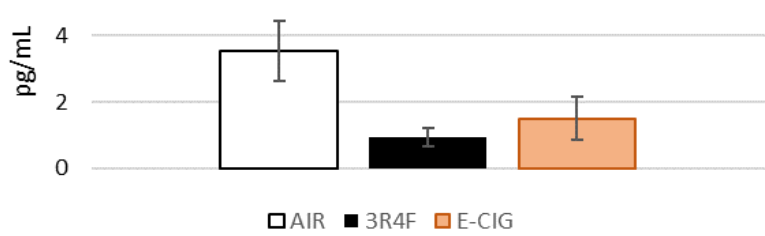

Figure 4.6 shows expression of cytokines in tissues highlighted in table 4.1 as either a tendency to be different (VEGF in BALF and lung, as well as GM-CSF in lung) or statistically different (IL- 6 in serum). Data are presented as mean \pm standard error. VEGF and GM-CSF analysis contained 6 animals per group. Number of animals in IL- 6 numbers were as follows, Air $(n=8), 3 R 4 F(n=7)$, E-cig $(n=9)$. 
Chapter 5: Discussion, Limitations and Future Directions 


\section{Discussion}

The principal finding of this study is that acute E-cigarette exposure causes peripheral blood vessel constriction, independent of nicotine, in the gluteus maximus muscle of mice. These effects are also observed with exposure to either $100 \%$ propylene glycol or vegetable glycerin, suggesting the base constituents of the E-liquid solution may be a key factor initiating vasoconstriction. Despite causing vasoconstriction, the ability of the endothelium to dilate to a vasodilatory stimulus (i.e. acetylcholine) remains largely unimpaired 1 hour after a single acute E-cigarette exposure. When a chronic E-cigarette paradigm is applied (i.e. 8 months of daily exposure) the expression of growth factors and cytokines are also altered in several tissues, suggesting altered immune and metabolic function. Taken together, these data show that alteration in vascular function are similar between E-cigarettes and traditional cigarettes which calls into question the safety of E-cigarettes and suggests that the long-term effect on blood vessels with E-cigarette use will likely be similar to those of regular cigarettes.

\section{Acute Time Course Responses}

We evaluated the time course response in two separate studies. Our first study observed the longest timeframe we could, using our intravital microscopy prep (approximately 2 hours). The second study was designed to provide a greater temporal resolution in the observed vasoconstriction response and determine if endothelial function was impaired. These series of experiments provide early evidence establishing the concept that acute E-cigarette exposure alters peripheral vascular tone. Figure 4.2 shows that E-cigarette exposure 
(independent of nicotine content) causes marked peripheral vasoconstriction, to a degree that mimics a 3R4F reference cigarette. The observed vasoconstriction lasts longer than 120 minutes post exposure in all cases. Further study will be needed to determine the total amount of time that vasoconstriction persists, this study is constrained by the survival time under anesthesia of mice in the prep.

We observed no significant differences in vessel tone when exposing animals to vapor with or without nicotine, suggesting that other mechanisms are responsible for altered tone after exposure. Mice were exposed to (nicotine-free) 100\% concentrations of either base component in E-liquid (i.e. PG-0 or VG-0) each produced vasoconstriction that mimics 3R4F cigarettes (Figure 4.2). Because PG-0 and VG-0 produced similar patterns of vasoconstriction, vaporizing the two components of the base liquid either, 1) produces similar breakdown products (i.e. carbonyl compounds), or 2) produces similar doses of particulate matter that could drive vasoconstriction. Other studies have reported increases in oxidative stress upon exposure to E-cigarette aerosols and extracts, suggesting that the mechanism of vasoconstriction we are observing in vivo may be a consequence of increased circulating reactive oxygen species (ROS) associated with oxidative stress (Anderson et al., 2016; Reidel et al., 2017; Ganapathy et al., 2017). ROS is known to be present in the vapor of E-cigarettes, as well as the smoke of traditional cigarettes (Sussan et al., 2015), and known to alter endothelial cell function in acute and chronic exposure paradigms (Cimmino et al., 2015; M. Kim et al., 2014).

Inhalation of particulate matter may also be an important factor since it has been shown to increase expression of endothelin-1 (Brook et al., 2002; Houde et al., 2016). If particulate 
matter is driving vasoconstriction, it is possible that endothelin-1 is involved. Aldehyde exposure, which is found in E-cigarette vapor, has been linked to cardiopulmonary toxicity which may involve the actions of TRPA-1 are thought to play a role (Conklin, 2016). One or both pathways may play a role in the effects of E-cigarettes on the peripheral vasculature.

Another potential mechanism of the vasoconstriction we observe is the TSP-1/CD47 pathway and its action on NO bioavailability. TSP-1 has been shown to be highly expressed in pulmonary injury (Mandler et al., 2018a). Preliminary data from our lab indicates that CD47 knockout mice (that don't express the TSP-1 receptor CD47) may, in part, be protected from vasoconstriction after exposure to E-cigarette vapor (data not shown). This could indicate that E-cigarettes might increase expression of TSP-1, which in turn could decrease bioavailable NO, resulting in increased basal vessel tone (or constriction). TSP-1 expression has also been shown to increase endothelial cell apoptosis (Nör, Mitra, \& Sutorik, 2000), chronic periodic elevation of TSP-1 may also contribute to increased arterial stiffness (through decreased NO bioavailability) and decreased endothelial response (by increasing endothelial apoptosis)(Nör et al., 2000). Arguing against a NO-mediated mechanism, however, is the observation that endothelial cell responses to $\mathrm{ACh}$ (i.e. vessel reactivity, discussed below) are largely unaffected the time point we studied (i.e. 1-hour post exposure).

Neural input may also play a role in our findings, the sympathetic nervous system alters vascular tone through the effects of norepinephrine (Malpas et al., 2001). Nicotine has also been shown to decrease the clearance of norepinephrine (Brees et al., 2008). There is also evidence that particulate matter inhalation (from diesel fuel exhaust) causes activation of the sympathetic nervous system, the mechanisms here, however, are unclear (Carll et al., 2013). If 
particulate matter drives sympathetic activation, vasoconstriction with exposure to E-cigarettes should be expected. It would also be expected however that heart rate would increase due to sympathetic stimulation, which our data does not show.

\section{Vascular Reactivity}

The ability of a blood vessel to dilate to acetylcholine is a measure of the ability endothelium to produce NO. Impaired NO synthesis has been shown to be an early predictor in the development of CVD (Beckman \& Koppenol, 1996; Jeremy et al., 2002). In vivo data in humans has shown that a single exposure to cigarette smoke impairs endothelium-dependent dilation (Lekakis et al., 1997). To assess endothelial dilatory capacity, we compared a preexposure acetylcholine dilation response, to identical doses of acetylcholine 50 minutes after exposure. Figure 4.4 shows that endothelial function was not different between pre- and postexposure dilation curves in either E-cigarettes or traditional cigarettes, except for the VG/PG-18 group. These data, while not in disagreement with previous findings published from our lab that chronic E-cigarette exposure causes impairment of endothelium-dependent dilation, does suggest that a single exposure is not enough to cause impaired endothelial cell response to a vasodilatory stimulus. Data illustrating the endothelial response of humans in response to Ecigarette exposure found significant impairment in ability to dilate 5-minutes post-exposure, indicating that endothelium impairment caused by a single E-cigarette exposure may be resolved sooner than 50 minutes (Carnevale et al., 2016), in which case, we would have missed detecting any impairment at our $>50$-minute time point. We did, however, observe that 
VG/PG-18 exposure group resulted in greater slope of the acetylcholine curve post exposure. This may be indicative of a role of nicotine, or some other vapor constituent in sensitizing the endothelium to acetylcholine. Nicotine may be the most logical factor because none of the other vapor exposed groups elicited this response, however the slope of 3R4F animals was not different. This suggests there may be some other factor (other than nicotine) involved. It is also possible that greater slope post exposure may be an artifact of dilating from a constricted point to the same diameter. This would mean endothelial function is not impaired, which is consistent with nicotine having a short half-life (9-10 mins) and therefore not effecting the endothelium 50-minutes post exposure (Siu \& Tyndale, 2007). There was also no verification of nicotine content in the serum of our mice, it is possible that levels of nicotine from 3R4F versus E-cigarette (with VG/PG-18) were different.

We monitored clinical variables (i.e. heart rate and body temperature) to evaluate the physiological stability of animals throughout the procedure. In general heart rate and body temperature were stable through all groups throughout the procedure, however VG/PG-18 shows a potential activation of the sympathetic nervous system with a sharp post exposure increase in heart rate. The sympathetic activation is tempting to attribute to nicotine, however (as mentioned before) since we do not yet know if serum levels of nicotine were the same between the groups, we cannot know if this was a nicotine mediated effect.

We also monitored bath temperature surrounding the externalized muscle, this temperature most closely measures the temperature of the micro-vessel environment. Variability in bath temperature in the pre-exposure portion of the experiment was likely due to the need of the apparatus used for heating the bath to warm up. While it is possible the lower 
pre-exposure bath temperatures could have influenced the reactivity responses, we would note that even the groups which has a constant temperature (i.e. sham and PG-0, Figure 4.5) exhibited no change in slope pre vs. post exposure. This suggests the absolute difference in temperature we observed in the VG/PG-18 and VG/PG-0 groups (delta temperature ranging from $0.8-1.6^{\circ} \mathrm{C}$ ) did not likely alter the outcome (i.e. no change in slope for VG/PG-0, and a steeper slope for VG/PG-18 post exposure). Supporting this notion, a previous study suggests that temperature differences this small should not greatly influence vessel responses, as endothelial dysfunction was found to not be impaired even after hypothermic circulatory arrest with a delta temperature change of $19^{\circ} \mathrm{C}$ (i.e. from $37^{\circ} \mathrm{C}$ to $18^{\circ} \mathrm{C}$ ) (Cooper et al., 2000). It should also be noted, the lower absolute temperature of the bath $\left(\sim 35^{\circ} \mathrm{C}\right)$ compared to body core temperature $\left(37^{\circ} \mathrm{C}\right)$ is also consistent with data frequently obtained during IVM procedures in peripheral skeletal muscle.

Lastly, our study also found no significant effect of sex on the vascular response to Ecigarette vapor. This is an interesting finding considering the known vaso-protective effects of estrogen (Collins, 1985). The protective effect of estrogen has, however been shown to decrease in response to increasing levels of oxidative stress such as exposure to E-cigarette vapor (Wassmann et al., 2001). This raises concerns about the vaso-protective effects of estrogen being diminished with chronic E-cigarette use. 


\section{Cytokine Analysis}

In prior work, we exposed mice to E-cigarette vapor for 8 months and report a significant decrease in vascular reactivity to acetylcholine (Olfert et al., 2018). As part of this project we sought to evaluate the response of pro-inflammatory cytokines and growth factors in tissues obtained from these mice. The lungs, BALF, serum and gastrocnemius muscle were chosen as key sites likely to be affected by vaping.

The only significant finding we observed was a decrease in serum levels of IL-6 in Ecigarette and 3R4F cigarette exposed mice. The levels of IL-6 in E-cigarette exposed mice behaved more like cigarette animals than air exposed controls. IL- 6 has been shown to contribute to immunity by stimulating immune cell response to pathogens (van der Poll et al., 1997). Decreases in serum IL-6 may be indicative of lower levels of immune system activity and contribute to the increased latency and rates of infections described above. IL-6 levels have been previously linked to the development of cardiovascular disease, as well as insulin resistance (De Mello et al., 2009). The observed changes in IL-6 with our study are consistent with these findings, the lack of changes observed with TNF- $\alpha$ is interesting in this context as IL-6 and TNF- $\alpha$ expression changes are generally thought to be concomitant (Azzolina, Bongiovanni, \& Lampiasi, 2003; De Mello et al., 2009). Other studies have shown increases in TNF- $\alpha$ in response to cigarette smoke and E-cigarette exposure ( Reidel. et al., 2017; Reidel et al., 2010).

VEGF levels tended to be lower in both lungs and BAL fluid, the role of VEGF in angiogenesis has been extensively characterized (Carvalho, Blank, \& Shoenfeld, 2007; Mayer et al., 2005). VEGF has been shown to play a role in vascular permeability, which may precede 
pulmonary inflammation in asthma patients (Khor et al., 2009). VEGF has also been shown to exert anti-apoptotic effects (Štefanec, 2000). Decreases in lung VEGF may indicate an increase in endothelial apoptosis. VEGF has also been linked to altering vascular permeability, a concern in the development of asthma (Khor et al., 2009). Asthma has been raised as a possible concern with chronic E-cigarette use by other groups (Higham et al., 2016), these results support that notion. further research will be needed to determine if the tendency observed in this study is physiologically significant.

GM-CSF in the lungs also tended to be different among groups, E-cigarette exposed animals showed lower concentrations of GM-CSF than cigarette exposed animals. High levels of GM-CSF have been attributed to the development of COPD phenotype in the past (Botelho et al., 2011). This may hint at COPD developing by different mechanisms with cigarette and Ecigarette use, but more research will be needed to determine if that is the case. The effects of GM-CSF on the peripheral vasculature are unclear and further research will be needed to determine the implications of this observation.

\section{Limitations}

A major concern surrounding all E-cigarette research is the highly variable way to use Ecigarettes, from the composition of liquids, temperature, voltage and puff topography. The exposure paradigm used in the acute studies (10 puffs, 5 second puff duration, 30 seconds apart) was meant to mimic the nicotine content of a single cigarette (Farsalinos, Spyrou, et al., 2015). In the chronic study we attempted to match for time and total particulate matter (TPM) 
exposure. Changing exposures may alter outcomes that we observe, but it should be noted that our exposure is light compared to that typically used in smoking-related studies. This means that, even at low levels of exposure, chronic E-cigarette use is likely to have significant effects toward cardiovascular health, suggesting that there may no real safe level of exposure.

Current generations of E-cigarettes allow for custom settings of power applied (i.e. watts, voltage) and temperature. In our study, we controlled the watts of the E-cigarette device, but the results are likely to vary if one uses different wattage or voltage (especially in chronic exposures). The flavor of the E-cigarette liquids is another variable that could have great influence on the presence of chemical breakdown products in the vapor created, not to mention that the settings of E-cigarette device may also alter the breakdown products of in the flavorings, resulting in a complex and potentially highly variable vapor composition. While it is not practical to test every combination, our data used both flavorings (i.e. VG/PG-18 and VG/PG-0) vs. no flavorings (i.e. PG-0 and VG-0) will little difference between the observed results. Thus, at least from a vascular response perspective (i.e. base tone and reactivity to stimulus), it would appear that French Vanilla flavoring had no additional effects. This does not, however, preclude the possibility that other combinations of either flavors or device settings might behave differently and produce worse outcomes.

To make in vivo measurements, we had to use a surgical prep under anesthesia. The use of anesthesia may have had some influence on the vasculature, but all groups were treated the same and animals served as their own control, therefore the responses we observed are expected to be qualitatively accurate, even if the heart rate (and other clinical variables) are quantitatively influenced by anesthesia. Prior studies also support the use of Inactin for IVM 
procedures due to the minimal cardiovascular side effects. The need for mice to be exposed through the endotracheal tube may have eliminated ancillary parasympathetic input that could come from flavoring activation on sweet tastes. Parasympathetic input in this context may counteract the effects of nicotine as a sympathomimetic. While the effects on peripheral vasculature are not likely to be significantly altered by parasympathetic input, the arteries that perfuse the digestive tract may be altered.

The biggest limitation, at this point, is the lack of confirmation that nicotine levels were the same in nicotine treated groups. While we have obtained serum post exposure these analyses have not yet been carried out. It is possible, that PG/VG-18 or 3R4F exposed animals received different levels of nicotine and increasing the relative dose of nicotine may increase the effects (i.e. increases in heart rate).

\section{Future work}

The primary focus of E-cigarette research moving forward should focus on how different alterations of settings and vapor composition on commercially available devices effect human health. Our studies highlight the implications of E-cigarette vapor on the vasculature with implications toward the immune system, but other body systems may be affected also. Our data suggest further research regarding the mechanism of peripheral vasoconstriction is warranted. There is, indeed, a complex interplay of multiple control systems that ultimately control vascular and immune cell function and understanding these pathways will allow insight into treatment options to potentially combat chronic disease. 
Oxidative damage to the endothelium has been a major player in the previous findings of our lab, and endothelial protection might be accomplished by simultaneous E-cigarette exposure and antioxidant administration. It would useful to evaluate the NO pathway by including administration of a nitric oxide synthase inhibitor (i.e. L-NAME) to the microvascular bed. If vasoconstriction is observed while eNOS is inhibited, then the bioavailability of NO in the observed vasoconstriction will be called into question. In the event inhibiting eNOS does not alter changes to vascular tone, administration of antioxidants may provide insight into mechanism, superoxide for example, may be produced by the breakdown of E-liquid and its effects on the endothelium may be prevented by administering superoxide dismutase (Förstermann \& Münzel, 2006; Raij et al., 2001). It would also be worthwhile to compare free radical content (using electron paramagnetic resonance studies) of the E-cigarette vapor and $3 R 4 F$ reference cigarettes. Understanding the relative exposure to free radicals can give insight into the oxidative load (and presumably endothelial damage) the animals are exposed to.

If the NO pathway is shown to be unaffected, testing the effects of vasoconstrictor elements would be a logical next step. Endothelin-1 would be particularly interesting since it is known to increase in the lung following inhaled exposure to particulate matter. ELISA assays or western blot techniques could be used to detect circulating levels of endothelin-1 in the serum. Because endothelin-1 expression is primarily regulated through gene expression real-time PCR techniques may be used to determine relative levels of gene expression if protein levels of endothelin-1 are not elevated (Houde et al., 2016; Marasciulo, Montagnani, \& Potenza, 2006; Shrestha et al., 2004). The vasodilatory drug Dilazep works by inhibiting endothelin-1 synthesis, 
administration of dilazep prior to E-cigarette exposure using an intravital approach may provide insight into the mechanism of vasoconstriction we observe (Shrestha et al., 2004).

More testing of the effects of E-cigarettes on the immune system are needed. Future work should also focus on the role of neutrophil infiltration in the lungs observed by other studies. Chronic exposure to E-cigarettes may cause clinically significant impairment in the lungs if the realistic levels of E-cigarette exposure drives the neutrophil inflammatory response. This would lead to concerns of the development of COPD with chronic E-cigarette use.

Newer E-cigarette products, that present unique ingredients and therefore vapor composition, are also beginning to appear on the market. These include vitamin vapes, cannabidiol vapor products and Juul. The claims of safety surrounding these products mimic those that surrounded E-cigarettes when they first appeared on the market, these claims are largely not scientifically validated. Many of these products use the same "base" solution as Ecigarettes. Because the effects of E-cigarettes on the vasculature are independent of nicotine and seem to be caused by the base solution itself, the outcomes of chronic use of these products is therefore likely to be similar even though the device system may vary. More studies are needed in the safety of inhaling the active ingredients of these products, and to the determine the effects of device settings (i.e. temperature, power, etc.) on producing the compounds inducing the changes in vascular function. 


\section{Works Cited}

Álvarez, Á., Cerdá-Nicolás, M., Abu Nabah, Y. N., Mata, M., Issekutz, A. C., Panés, J., ... Sanz, M. J. (2004). Direct evidence of leukocyte adhesion in arterioles by angiotensin II. Blood, 104(2), 402-408. https://doi.org/10.1182/blood-2003-08-2974

Ambrose, J. A., \& Barua, R. S. (2004). The pathophysiology of cigarette smoking and cardiovascular disease: An update. Journal of the American College of Cardiology, 43(10), 1731-1737. https://doi.org/10.1016/j.jacc.2003.12.047

American S' Perspectives on E-Cigarettes. (2015), (October).

Anderson, C., Majeste, A., Hanus, J., \& Wang, S. (2016). E-Cigarette Aerosol Exposure Induces Reactive Oxygen Species, DNA Damage, and Cell Death in Vascular Endothelial Cells. Toxicological Sciences, 154(2), 332-340. https://doi.org/10.1093/toxsci/kfw166

Article, O. (1992). Clinical Investigator and blood-brain barrier integrity in the cat, 210-217.

Article, O. (2011). High Blood Viscosity Is Closely Associated With Cigarette Smoking and Markedly Reduced by Smoking Cessation, 75(January). https://doi.org/10.1253/circj.CJ-100335

Asano, H., Horinouchi, T., Mai, Y., Sawada, O., Fujii, S., Nishiya, T., ... Miwa, S. (2012). Nicotineand Tar-Free Cigarette Smoke Induces Cell Damage Through Reactive Oxygen Species Newly Generated by PKC-Dependent Activation of NADPH Oxidase. Journal of Pharmacological Sciences, 118(2), 275-287. https://doi.org/10.1254/jphs.11166FP

Azzolina, A., Bongiovanni, A., \& Lampiasi, N. (2003). Substance P induces TNF- $\alpha$ and IL-6 
production through NFKB in peritoneal mast cells. Biochimica et Biophysica Acta Molecular Cell Research, 1643(1-3), 75-83. https://doi.org/10.1016/j.bbamcr.2003.09.003

B., R., A.A., F., G., R., P., H., N.E., A., I., J., \& R., T. (2017). E-cigarette user airway secretions exhibit increased leukocyte derived inflammatory mediator proteins. American Journal of Respiratory and Critical Care Medicine, 195, 120100. https://doi.org/http://dx.doi.org/10.1164/ajrccm-conference.2017.A16

Banday, A. A., \& Lokhandwala, M. F. (2008). Oxidative stress-induced renal angiotensin AT1 receptor upregulation causes increased stimulation of sodium transporters and hypertension. American Journal of Physiology. Renal Physiology, 295(3), F698-706. https://doi.org/10.1152/ajprenal.90308.2008

Barnes, P. J. (2001). Th2 cytokines and asthma: An introduction. Respiratory Research, 2(2), 6465. https://doi.org/10.1186/rr39

Bearden, S. E., Payne, G. W., Chisty, A., \& Segal, S. S. (2004). Arteriolar network architecture and vasomotor function with ageing in mouse gluteus maximus muscle. Journal of Physiology, 561(2), 535-545. https://doi.org/10.1113/jphysiol.2004.068262

Beckman, J., \& Koppenol, W. (1996). Nitric oxide, superoxide, and peroxynitrite: the good, the bad, and ugly. The American Journal of Physiology, 271(73), C1424-C1437. https://doi.org/10.1146/annurev.arplant.50.1.277

Behar, R. Z., Davis, B., Wang, Y., Bahl, V., Lin, S., \& Talbot, P. (2014). Identification of toxicants in cinnamon-flavored electronic cigarette refill fluids. Toxicology in Vitro, 28(2), 198-208. 
https://doi.org/10.1016/j.tiv.2013.10.006

Beltowski, J., Wójcicka, G., Marciniak, A., \& Jamroz, A. (2004). Oxidative stress, nitric oxide production, and renal sodium handling in leptin-induced hypertension. Life Sciences, 74(24), 2987-3000. https://doi.org/10.1016/j.Ifs.2003.10.029

Black, C. E., Huang, N., Neligan, P. C., Levine, R. H., Lipa, J. E., Lintlop, S., ... Pang, C. Y. (2001). Effect of nicotine on vasoconstrictor and vasodilator responses in human skin vasculature. American Journal of Physiology-Regulatory, Integrative and Comparative Physiology, 281(4), R1097-R1104. https://doi.org/10.1152/ajpregu.2001.281.4.R1097

Boos, C. J., Balakrishnan, B., Blann, A. D., \& Lip, G. Y. H. (2008). The relationship of circulating endothelial cells to plasma indices of endothelial damage/dysfunction and apoptosis in acute coronary syndromes: Implications for prognosis. Journal of Thrombosis and Haemostasis, 6(11), 1841-1850. https://doi.org/10.1111/j.1538-7836.2008.03148.x

Boris Reidel, Giorgia Radicioni, Phillip Clapp, Amina A Ford, Sabri Abdelwahab, Meghan E Rebuli, Prashamsha Haridass, Neil E Alexis, I. J. and, \& Kesimer, M. (2010). E-Cigarette Use Causes a Unique Innate Immune Response in the Lung, Involving Increased Neutrophilic Activation and Altered Mucin Secretion. https://doi.org/10.2527/jas2016.0863

Botelho, F. M., Nikota, J. K., Bauer, C., Davis, N. H. E., Cohen, E. S., Anderson, I. K., ... Sleeman, M. A. (2011). A mouse GM-CSF receptor antibody attenuates neutrophilia in mice exposed to cigarette smoke. European Respiratory Journal, 38(2), 285-294.

https://doi.org/10.1183/09031936.00076210 
Brees, D. J., Elwell, M. R., Tingley, F. D., Sands, S. B., Jakowski, A. B., Shen, A. C., ... Finkelstein, M. B. (2008). Pharmacological Effects of Nicotine on Norepinephrine Metabolism in Rat Brown Adipose Tissue: Relevance to Nicotinic Therapies for Smoking Cessation. Toxicologic Pathology, 36(4), 568-575. https://doi.org/10.1177/0192623308317424

Brook, R. D., Brook, J. R., Urch, B., Vincent, R., Rajagopalan, S., \& Silverman, F. (2002). Inhalation of fine particulate air pollution and ozone causes acute arterial vasoconstriction in healthy adults. Circulation, 105(13), 1534-1536.

https://doi.org/10.1161/01.CIR.0000013838.94747.64

Brown, J., Beard, E., Kotz, D., Michie, S., \& West, R. (2014). Real-world effectiveness of ecigarettes when used to aid smoking cessation: A cross-sectional population study. Addiction, 109(9), 1531-1540. https://doi.org/10.1111/add.12623

Buettner-Schmidt, K., Miller, D. R., \& Balasubramanian, N. (2016). Electronic Cigarette Refill Liquids: Child-Resistant Packaging, Nicotine Content, and Sales to Minors. Journal of Pediatric Nursing, 31(4), 373-379. https://doi.org/10.1016/j.pedn.2016.03.019

Bullen, C., Howe, C., Laugesen, M., McRobbie, H., Parag, V., Williman, J., \& Walker, N. (2013). Electronic cigarettes for smoking cessation: A randomised controlled trial. The Lancet, 382(9905), 1629-1637. https://doi.org/10.1016/S0140-6736(13)61842-5

Bullen, C., McRobbie, H., Thornley, S., Glover, M., Lin, R., \& Laugesen, M. (2010). Effect of an electronic nicotine delivery device (e cigarette) on desire to smoke and withdrawal, user preferences and nicotine delivery: Randomised cross-over trial. Tobacco Control, 19(2), 98-103. https://doi.org/10.1136/tc.2009.031567 
Caponnetto, P., Campagna, D., Cibella, F., Morjaria, J. B., Caruso, M., Russo, C., \& Polosa, R. (2013). EffiCiency and Safety of an eLectronic cigAreTte (ECLAT) as Tobacco Cigarettes Substitute: A Prospective 12-Month Randomized Control Design Study. PLoS ONE, 8(6), 112. https://doi.org/10.1371/journal.pone.0066317

Carll, A. P., Hazari, M. S., Perez, C. M., Krantz, Q. T., King, C. J., Haykal-Coates, N., ... Farraj, A. K. (2013). An autonomic link between inhaled diesel exhaust and impaired cardiac performance: Insight from treadmill and dobutamine challenges in heart failure-prone rats. Toxicological Sciences, 135(2), 425-436. https://doi.org/10.1093/toxsci/kft155

Carnevale, R., Sciarretta, S., Violi, F., Nocella, C., Loffredo, L., Perri, L., ... Frati, G. (2016). Acute Impact of Tobacco vs Electronic Cigarette Smoking on Oxidative Stress and Vascular Function. Chest, 150(3), 606-612. https://doi.org/10.1016/j.chest.2016.04.012

Carvalho, J. F., Blank, M., \& Shoenfeld, Y. (2007). Vascular endothelial growth factor (VEGF) in autoimmune diseases. Journal of Clinical Immunology, 27(3), 246-256. https://doi.org/10.1007/s10875-007-9083-1

Cassee, F. R., de Burbure, C. Y., Rambali, B., Vleeming, W., van de Kuil, A., van Steeg, H., ... Opperhuizen, A. (2008). Subchronic inhalation of mixtures of cigarette smoke constituents in Xpa-/-p53+/- knock-out mice: A comparison of intermittent with semi-continuous exposure to acetaldehyde, formaldehyde, and acrolein. Food and Chemical Toxicology, 46(2), 527-536. https://doi.org/10.1016/j.fct.2007.08.043

Castranova, V., Asgharian, B., Sayre, P., Virginia, W., \& Carolina, N. (2016). HHS Public Access, 17(10), 1922-2013. https://doi.org/10.1080/10937404.2015.1051611.INHALATION 
Celermajer, D. S., Sorensen, K. E., Georgakopoulos, D., Bull, C., Thomas, O., Robinson, J., \& Deanfield, J. E. (1993). Cigarette smoking is associated with dose-related and potentially reversible impairment of endothelium-dependent dilation in healthy young adults. Circulation, 88(5), 2149-2155. https://doi.org/10.1161/01.CIR.88.5.2149

Center for Disease Control and Prevention. (2011). Adult Smoking in the US. Cdc, (September), 1-4.

Chiou, C. Y., Trzeciakowski, J., \& Klein, D. C. (1976). Histamine mediation of nicotine effects on postganglionic sympathetic neuroeffector junctions. Neuropharmacology, 15(11), 689693. https://doi.org/10.1016/0028-3908(76)90038-1

Churg, A., Dai, J., Tai, H., Xie, C., \& Wright, J. L. (2002). Tumor necrosis factor- $\alpha$ is central to acute cigarette smoke-induced inflammation and connective tissue breakdown. American Journal of Respiratory and Critical Care Medicine, 166(6), 849-854.

https://doi.org/10.1164/rccm.200202-0970C

CIGARETTE SMOKE ELICITS LEUKOCYTE ADHESION TO. (n.d.).

Cigarette smoke extract induced cytokine and chemokine. (n.d.).

Cimmino, G., Cirillo, P., Ragni, M., Conte, S., Uccello, G., \& Golino, P. (2015). Reactive oxygen species induce a procoagulant state in endothelial cells by inhibiting tissue factor pathway inhibitor. Journal of Thrombosis and Thrombolysis, 40(2), 186-192.

https://doi.org/10.1007/s11239-015-1199-1

Clapp, B. R., Hingorani, A. D., Kharbanda, R. K., Mohamed-Ali, V., Stephens, J. W., Vallance, P., \& 
MacAllister, R. J. (2004). Inflammation-induced endothelial dysfunction involves reduced nitric oxide bioavailability and increased oxidant stress. Cardiovascular Research, 64(1), 172-178. https://doi.org/10.1016/j.cardiores.2004.06.020

Clapp, P. W., \& Jaspers, I. (2017). Electronic Cigarettes: Their Constituents and Potential Links to Asthma. Current Allergy and Asthma Reports, 17(11), 79. https://doi.org/10.1007/s11882017-0747-5

Collins, P. (1985). In Vitro and In vivo effects of estrogen on nitric oxide and the endothelium, 3, 24.

Conklin, D. J. (2016). Acute cardiopulmonary toxicity of inhaled aldehydes: role of TRPA1. Annals of the New York Academy of Sciences, 1374(1), 59-67. https://doi.org/10.1111/nyas.13055

Cooper, W. A., Duarte, I. G., Thourani, V. H., Nakamura, M., Wang, N., lii, W. M. B., ... Hospital, L. (2000). Multisystem Vascular Endothelial Dysfunction and Apoptosis. Annals of Thoracic Surgery, The, 4975(99).

Correa, J. B., Brandon, K. O., Thomas, H., Meltzer, L. R., Simmons, V. N., \& Hoehn, H. J. (2018). Electronic cigarette use among patients with cancer : Reasons for use, beliefs, and patient - provider communication, (February), 1-8. https://doi.org/10.1002/pon.4721

Csiszar, A., Ungvari, Z., Koller, A., Edwards, J. G., \& Kaley, G. (2004). Proinflammatory phenotype of coronary arteries promotes endothelial apoptosis in aging. Physiological Genomics, 17(1), 21-30. https://doi.org/10.1152/physiolgenomics.00136.2003 
De Mello, V. D. F., Lankinen, M., Schwab, U., Kolehmainen, M., Lehto, S., Seppänen-Laakso, T., ... Erkkilä, A. T. (2009). Link between plasma ceramides, inflammation and insulin resistance: Association with serum IL-6 concentration in patients with coronary heart disease. Diabetologia, 52(12), 2612-2615. https://doi.org/10.1007/s00125-009-1482-9

Drannik, A. G., Pouladi, M. A., Robbins, C. S., Goncharova, S. I., Kianpour, S., \& Stämpfli, M. R. (2004). Impact of cigarette smoke on clearance and inflammation after Pseudomonas aeruginosa infection. American Journal of Respiratory and Critical Care Medicine, 170(11), 1164-1171. https://doi.org/10.1164/rccm.200311-15210C

Fang, Q. (2006). Inhibition of NADPH oxidase improves impaired reactivity of pial arterioles during chronic exposure to nicotine. Journal of Applied Physiology, 100(2), 631-636. https://doi.org/10.1152/japplphysiol.00975.2005

Farsalinos, K. E., Gillman, G., Poulas, K., \& Voudris, V. (2015). Tobacco-Specific Nitrosamines in Electronic Cigarettes: Comparison between liquid and aerosol levels. International Journal of Environmental Research and Public Health, 12(8), 9046-9053. https://doi.org/10.3390/ijerph120809046

Farsalinos, K. E., Spyrou, A., Stefopoulos, C., Tsimopoulou, K., Kourkoveli, P., Tsiapras, D., ... Voudris, V. (2015). Nicotine absorption from electronic cigarette use: Comparison between experienced consumers (vapers) and naïve users (smokers). Scientific Reports, 5(June), 18. https://doi.org/10.1038/srep11269

Félétou, M., Huang, Y., \& Vanhoutte, P. M. (2011). Endothelium-mediated control of vascular tone: COX-1 and COX-2 products. British Journal of Pharmacology, 164(3), 894-912. 
https://doi.org/10.1111/j.1476-5381.2011.01276.x

Förstermann, U., \& Münzel, T. (2006). Endothelial nitric oxide synthase in vascular disease:

From marvel to menace. Circulation, 113(13), 1708-1714.

https://doi.org/10.1161/CIRCULATIONAHA.105.602532

Frey, L. T., \& Tilburg, W. C. (2016). Child-resistant packaging for e-liquid: A review of us state legislation. American Journal of Public Health, 106(2), 266-268.

https://doi.org/10.2105/AJPH.2015.302957

Ganapathy, V., Manyanga, J., Brame, L., McGuire, D., Sadhasivam, B., Floyd, E., ... Queimado, L. (2017). Electronic cigarette aerosols suppress cellular antioxidant defenses and induce significant oxidative DNA damage. PLoS ONE, 12(5), 1-20.

https://doi.org/10.1371/journal.pone.0177780

Garcia-Arcos, I., Geraghty, P., Baumlin, N., Campos, M., Dabo, A. J., Jundi, B., ... Foronjy, R. (2016). Chronic electronic cigarette exposure in mice induces features of COPD in a nicotine-dependent manner. Thorax, 71(12), 1119-1129.

https://doi.org/10.1136/thoraxjnl-2015-208039

Gewaltig, M. T., \& Kojd, G. (2002). V asoprotection by nitric oxide: mechanisms and therapeutic potential. Cardiovascular Research, 55(June), 250-260.

Giunzioni, I., Bonomo, A., Bishop, E., Castiglioni, S., Corsini, A., \& Bellosta, S. (2014). Cigarette smoke condensate affects monocyte interaction with endothelium. Atherosclerosis, 234(2), 383-390. https://doi.org/10.1016/j.atherosclerosis.2014.03.029 
Han, Y. P., Tuan, T. L., Wu, H., Hughes, M., \& Garner, W. L. (2001). TNF-alpha stimulates activation of pro-MMP2 in human skin through NF-(kappa)B mediated induction of MT1MMP. Journal of Cell Science, 114(Pt 1), 131-139.

https://doi.org/10.1016/j.bbi.2008.05.010

Haustein, K., Krause, J., Haustein, H., Rasmussen, T., \& Cort, N. (2002). Effects of cigarette smoking or nicotine replacement on cardiovascular risk factors and parameters of haemorheology, 130-139.

Hess, C. A., Olmedo, P., Navas-Acien, A., Goessler, W., Cohen, J. E., \& Rule, A. M. (2017). Ecigarettes as a source of toxic and potentially carcinogenic metals. Environmental Research, 152(June 2016), 221-225. https://doi.org/10.1016/j.envres.2016.09.026

Higham, A., Rattray, N. J. W., Dewhurst, J. A., Trivedi, D. K., Fowler, S. J., Goodacre, R., \& Singh, D. (2016). Electronic cigarette exposure triggers neutrophil inflammatory responses. Respiratory Research, 17(1), 1-11. https://doi.org/10.1186/s12931-016-0368-x

Hilgers, R. H. P., \& De Mey, J. G. R. (2009). Myoendothelial coupling in the mesenteric arterial bed; Segmental differences and interplay between nitric oxide and endothelin-1. British Journal of Pharmacology, 156(8), 1239-1247. https://doi.org/10.1111/j.14765381.2009.00128.x

Hilton, S. M. (1954). The effects of nicotine on the blood vessels of skeletal muscle in the cat. An investigation of vasomotor axon reflexes. The Journal of Physiology, 123(2), 289-300. https://doi.org/10.1113/jphysiol.1954.sp005051 
Hoenderdos, K., \& Condliffe, A. (2013). The neutrophil in chronic obstructive pulmonary disease: Too little, too late or too much, too soon? American Journal of Respiratory Cell and Molecular Biology, 48(5), 531-539. https://doi.org/10.1165/rcmb.2012-0492TR

Houde, M., Desbiens, L., \& D’Orléans-Juste, P. (2016). Endothelin-1: Biosynthesis, Signaling and Vasoreactivity. Advances in Pharmacology, 77, 143-175. https://doi.org/10.1016/bs.apha.2016.05.002

Hwang, J. H., Lyes, M., Sladewski, K., Enany, S., McEachern, E., Mathew, D. P., ... Crotty Alexander, L. E. (2016). Electronic cigarette inhalation alters innate immunity and airway cytokines while increasing the virulence of colonizing bacteria. Journal of Molecular Medicine, 94(6), 667-679. https://doi.org/10.1007/s00109-016-1378-3

Ikonomidis, I., Vlastos, D., Kourea, K., Kostelli, G., Varoudi, M., Pavlidis, G., ... Lekakis, J. (2018). Electronic Cigarette Smoking Increases Arterial Stiffness and Oxidative Stress to a Lesser Extent Than a Single Conventional Cigarette. Circulation, 137(3), 303-306. https://doi.org/10.1161/CIRCULATIONAHA.117.029153

Ingebrethsen, B. J., Cole, S. K., \& Alderman, S. L. (2012). Electronic cigarette aerosol particle size distribution measurements. Inhalation Toxicology, 24(14), 976-984. https://doi.org/10.3109/08958378.2012.744781

Jaimes, E. a, Galceran, J. M., \& Raij, L. (1998). Angiotensin II induces superoxide anion production by mesangial cells. Kidney Int, 54(3), 775-784. https://doi.org/10.1046/j.15231755.1998.00068.x 
Jarvis, M. J. (2004). Why people smoke. Bmj, 328(7434), 277.

https://doi.org/10.1136/bmj.328.7434.277

Jeremy, J. Y., Yim, A. P., Wan, S., \& Angelini, G. D. (2002). Oxidative stress, nitric oxide, and vascular disease. Journal of Cardiac Surgery, 17(4), 324-327.

Kampfrath, T., Maiseyeu, A., Ying, Z., Shah, Z., Deiuliis, J. A., Xu, X., ... Rajagopalan, S. (2011).

Chronic fine particulate matter exposure induces systemic vascular dysfunction via NADPH oxidase and TLR4 pathways. Circulation Research, 108(6), 716-726.

https://doi.org/10.1161/CIRCRESAHA.110.237560

Khor, Y. H., Teoh, A. K. Y., Lam, S. M., Mo, D. C. Q., Weston, S., Reid, D. W., \& Walters, E. H. (2009). Increased vascular permeability precedes cellular inflammation as asthma control deteriorates. Clinical and Experimental Allergy, 39(11), 1659-1667. https://doi.org/10.1111/j.1365-2222.2009.03349.x

Kim, H. J., \& Shin, H. S. (2013). Determination of tobacco-specific nitrosamines in replacement liquids of electronic cigarettes by liquid chromatography-tandem mass spectrometry. Journal of Chromatography A. https://doi.org/10.1016/j.chroma.2013.03.035

Kim, M., Han, C.-H., \& Lee, M.-Y. (2014). NADPH Oxidase and the Cardiovascular Toxicity Associated with Smoking. Toxicological Research, 30(3), 149-157. https://doi.org/10.5487/TR.2014.30.3.149

Kitta, Y., Obata, J. ei, Nakamura, T., Hirano, M., Kodama, Y., Fujioka, D., ... Kugiyama, K. (2009). Persistent Impairment of Endothelial Vasomotor Function Has a Negative Impact on 
Outcome in Patients With Coronary Artery Disease. Journal of the American College of Cardiology, 53(4), 323-330. https://doi.org/10.1016/j.jacc.2008.08.074

Kosmider, L., Sobczak, A., Fik, M., Knysak, J., Zaciera, M., Kurek, J., \& Goniewicz, M. L. (2014). Carbonyl compounds in electronic cigarette vapors: Effects of nicotine solvent and battery output voltage. Nicotine and Tobacco Research, 16(10), 1319-1326.

https://doi.org/10.1093/ntr/ntu078

Kubes, P., Suzuki, M., \& Granger, D. N. (1991). Nitric oxide: an endogenous modulator of leukocyte adhesion. Proceedings of the National Academy of Sciences, 88(11), 4651-4655. https://doi.org/10.1073/pnas.88.11.4651

Kuzkaya, N., Weissmann, N., Harrison, D. G., \& Dikalov, S. (2003). Interactions of peroxynitrite, tetrahydrobiopterin, ascorbic acid, and thiols: Implications for uncoupling endothelial nitric-oxide synthase. Journal of Biological Chemistry, 278(25), 22546-22554. https://doi.org/10.1074/jbc.M302227200

Lawler, J. (2002). Thrombospondin-1 as an endogenous inhibitor of angiogenesis and tumor growth. J Cell Mol Med, 6(1), 1-12. https://doi.org/006.001.01 [pii]

Lehr, H. A. (2000). Microcirculatory dysfunction induced by cigarette smoking. Microcirculation (New York, N.Y. : 1994), 7(6 Pt 1), 367-84. https://doi.org/10.1111/j.15498719.2000.tb00135.x

Lehr, H. A., Frei, B., \& Arfors, K. E. (1994). Vitamin C prevents cigarette smoke-induced leukocyte aggregation and adhesion to endothelium in vivo. Proceedings of the National 
Academy of Sciences of the United States of America, 91(16), 7688-92.

https://doi.org/10.1073/pnas.91.16.7688

Lekakis, J., Papamichael, C., Vemmos, C., Nanas, J., Kontoyannis, D., Stamatelopoulos, S., \& Moulopoulos, S. (1997). Effect of Acute Cigarette Smoking on Endothelium-Dependent Brachial Artery Dilatation in Healthy Individuals. American Journal of Cardiology, 79(4), 529-531. https://doi.org/10.1016/S0002-9149(96)00805-3

Leventhal, A. M., Strong, D. R., Kirkpatrick, M. G., Unger, J. B., Sussman, S., Riggs, N. R., ... Audrain-McGovern, J. (2015). Association of electronic cigarette use with initiation of combustible tobacco product smoking in early adolescence. JAMA - Journal of the American Medical Association, 314(7), 700-707. https://doi.org/10.1001/jama.2015.8950

Liu, B., Qu, L., \& Yan, S. (2015). Cyclooxygenase-2 promotes tumor growth and suppresses tumor immunity. Cancer Cell International, 15(1), 2-7. https://doi.org/10.1186/s12935015-0260-7

Madhur, M. S., Lob, H. E., McCann, L. A., Iwakura, Y., Blinder, Y., Guzik, T. J., \& Harrison, D. G. (2010). Interleukin 17 promotes angiotensin II-induced hypertension and vascular dysfunction. Hypertension, 55(2), 500-507. https://doi.org/10.1161/HYPERTENSIONAHA.109.145094

Malpas, S. C., Leonard, B. L., Guild, S., Ringwood, J. V, Navakatikyan, M., Austin, P. C., ... Burgess, D. E. (2001). The Sympathetic Nervous System 's Role in Regulating Blood Pressure Variability, (April). 
Mandler, W. K., Nurkiewicz, T. R., Porter, D. W., Kelley, E. E., \& Olfert, I. M. (2018a).

Microvascular Dysfunction Following Multiwalled Carbon Nanotube Exposure Is Mediated

by Thrombospondin-1 Receptor CD47, (June), 1-10. https://doi.org/10.1093/toxsci/kfy120

Mandler, W. K., Nurkiewicz, T. R., Porter, D. W., Kelley, E. E., \& Olfert, I. M. (2018b).

Microvascular Dysfunction Following Multiwalled Carbon Nanotube Exposure Is Mediated

by Thrombospondin-1 Receptor CD47, (June), 1-10. https://doi.org/10.1093/toxsci/kfy120

Manigrasso, M., Buonanno, G., Stabile, L., Morawska, L., \& Avino, P. (2015). Particle doses in the pulmonary lobes of electronic and conventional cigarette users. Environmental Pollution, 202, 24-31. https://doi.org/10.1016/j.envpol.2015.03.008

Marasciulo, F., Montagnani, M., \& Potenza, M. (2006). Endothelin-1: The Yin and Yang on Vascular Function. Current Medicinal Chemistry, 13(14), 1655-1665. https://doi.org/10.2174/092986706777441968

Mayer, H., Bertram, H., Lindenmaier, W., Korff, T., Weber, H., \& Weich, H. (2005). Vascular endothelial growth factor (VEGF-A) expression in human mesenchymal stem cells: Autocrine and paracrine role on osteoblastic and endothelial differentiation. Journal of Cellular Biochemistry, 95(4), 827-839. https://doi.org/10.1002/jcb.20462

Mayhan, W. G. (1999). Acute infusion of nicotine potentiates norepinephrine-induced vasoconstriction in the hamster cheek pouch. Journal of Laboratory and Clinical Medicine, 133(1), 48-54. https://doi.org/10.1053/lc.1999.v133.a94238

Mayhan, W. G., \& Sharpe, G. M. (1998). Nicotine impairs histamine-induced increases in 
macromolecular efflux: role of oxygen radicals. Journal of Applied Physiology (Bethesda, Md. : 1985), 84(5), 1589-1595. https://doi.org/10.1152/jappl.1998.84.5.1589

McAuley, T. R., Hopke, P. K., Zhao, J., \& Babaian, S. (2012). Comparison of the effects of ecigarette vapor and cigarette smoke on indoor air quality. Inhalation Toxicology, 24(12), 850-857. https://doi.org/10.3109/08958378.2012.724728

Mercer, P. F., Shute, J. K., Bhowmik, A., Donaldson, G. C., Wedzicha, J. A., \& Warner, J. A. (2005). MMP-9, TIMP-1 and inflammatory cells in sputum from COPD patients during exacerbation. Respiratory Research, 6, 1-10. https://doi.org/10.1186/1465-9921-6-151

Mezzano, S. A., Ruiz-ortega, M., Egido, J., Mezzano, S. A., Ruiz-ortega, M., \& Egido, J. (2001). Angiotensin II and Renal Fibrosis, 635-638. https://doi.org/10.1161/hy09t1.094234

Moheimani, R. S., Bhetraratana, M., Peters, K. M., Yang, B. K., Yin, F., Gornbein, J., ... Middlekauff, H. R. (2017). Sympathomimetic effects of acute e-cigarette use: Role of nicotine and non-nicotine constituents. Journal of the American Heart Association, 6(9), 111. https://doi.org/10.1161/JAHA.117.006579

Muthumalage, T., Prinz, M., Ansah, K. O., Gerloff, J., Sundar, I. K., \& Rahman, I. (2018). Inflammatory and oxidative responses induced by exposure to commonly used e-cigarette flavoring chemicals and flavored e-liquids without nicotine. Frontiers in Physiology, 8(JAN), 1-13. https://doi.org/10.3389/fphys.2017.01130

Nayir, E., Karacabey, B., Kirca, O., \& Ozdogan, M. (2016). Electronic cigarette (e-cigarette). Journal of Oncological Science, 2(1), 16-20. https://doi.org/10.1016/j.jons.2016.04.001 
Neppl, R. L., Lubomirov, L. T., Momotani, K., Pfitzer, G., Eto, M., \& Somlyo, A. V. (2009).

Thromboxane A2-induced bi-directional regulation of cerebral arterial tone. Journal of Biological Chemistry, 284(10), 6348-6360. https://doi.org/10.1074/jbc.M807040200

Nör, J., Mitra, R., \& Sutorik, M. (2000). Thrombospondin-1 induces endothelial cell apoptosis and inhibits angiogenesis by activating the caspase death pathway. Journal of Vascular ..., 37, 209-218.

Of, S., Reactive, E., Species, O., The, I. N., \& Hepatocytes, F. R. A. T. (2004). Original Contribution, 36(1), 16-26. https://doi.org/10.1016/j.freeradbiomed.2003.09.020

Ogunwale, M. A., Li, M., Ramakrishnam Raju, M. V., Chen, Y., Nantz, M. H., Conklin, D. J., \& Fu, X. A. (2017). Aldehyde Detection in Electronic Cigarette Aerosols. ACS Omega, 2(3), 12071214. https://doi.org/10.1021/acsomega.6b00489

Olfert, I. M., Devallance, E., Hoskinson, H., Branyan, K. W., Clayton, S., Pitzer, C. R., ... Olfert, I. M. (2018). Chronic exposure to electronic cigarette (E-cig) results in impaired cardiovascular function in mice.

Orellana-Barrios, M. A., Payne, D., Medrano-Juarez, R. M., Yang, S., \& Nugent, K. (2016). Electronic Cigarettes for Smoking Cessation. American Journal of the Medical Sciences, 352(4), 420-426. https://doi.org/10.1016/j.amjms.2016.07.013

PRIETO, A., REYES, E., BERNSTEIN, E. D., MARTINEZ, B., MONSERRAT, J., IZQUIERDO, J. L., ... ALVAREZ-MON, M. (2001). Defective Natural Killer and Phagocytic Activities in Chronic Obstructive Pulmonary Disease Are Restored by Glycophosphopeptical (Inmunoferón). 
American Journal of Respiratory and Critical Care Medicine, 163(7), 1578-1583.

https://doi.org/10.1164/ajrccm.163.7.2002015

Putzhammer, R., Doppler, C., Jakschitz, T., Heinz, K., Förste, J., Danzl, K., ... Bernhard, D. (2016). Vapours of US and EU market leader electronic cigarette brands and liquids are cytotoxic for human vascular endothelial cells. PLOS ONE, 11(6), 1-15. https://doi.org/10.1371/journal.pone.0157337

Qasim, H., Karim, Z. A., Rivera, J. O., Khasawneh, F. T., \& Alshbool, F. Z. (2017). Impact of electronic cigarettes on the cardiovascular system. Journal of the American Heart Association, 6(9). https://doi.org/10.1161/JAHA.117.006353

Raij, L., DeMaster, E. G., \& Jaimes, E. a. (2001). Cigarette smoke-induced endothelium dysfunction: role of superoxide anion. Journal of Hypertension, 19, 891-897. https://doi.org/10.1097/00004872-200105000-00009

Raveendran, M., Wang, J., Senthil, D., Wang, J., Utama, B., Shen, Y., ... Wang, X. L. (2005). Endogenous nitric oxide activation protects against cigarette smoking induced apoptosis in endothelial cells. FEBS Letters, 579(3), 733-740. https://doi.org/10.1016/j.febslet.2004.12.052

Reid, P., \& Sallenave, J.-. (2003). Cytokines in the Pathogenesis of Chronic Obstructive Pulmonary Disease. Current Pharmaceutical Design, 9(1), 25-38. https://doi.org/10.2174/1381612033392440

Rubenstein, I., Yong, T., Rennard, S. I., \& Mayhan, W. G. (1991). Cigarette smoke extract 
attenuates endothelium-dependent arteriolar dilatation in vivo. American Journal of Physiology - Heart and Circulatory Physiology, 261(6), H1913-H1918.

Schober, W., Szendrei, K., Matzen, W., Osiander-Fuchs, H., Heitmann, D., Schettgen, T., ... Fromme, H. (2014). Use of electronic cigarettes (e-cigarettes) impairs indoor air quality and increases FeNO levels of e-cigarette consumers. International Journal of Hygiene and Environmental Health, 217(6), 628-637. https://doi.org/10.1016/j.ijheh.2013.11.003

Seifter, J. L. (2014). Hidden Formaldehyde in E-Cigarette Aerosols. New England Journal of Medicine, 371(19), 1821-1831. https://doi.org/10.1056/NEJMra1215672

Shrestha, B., Hidai, C., Ikeda, H., Okada-ohno, M., Kasanuki, H., \& Kawana, M. (2004). Endothelin-1 Gene Expression in Endothelial Cells Is Potently Inhibited by a Vasodilator, Dilazep, 409-415. https://doi.org/10.1291/hypres.27.409

Siu, E., \& Tyndale, R. (2007). Characterization and comparison of nicotine and cotinine metabolism in vitro and in vivo in DBA/2 and C57BL/6 mice. Molecular Pharmacology, 71(3), 826-834. https://doi.org/10.1124/mol.106.032086.found

Smoking, C., \& Disease, C. (2018). Cigarette Smoking, Cardiovascular Disease, and Stroke, 1-9.

Soule, E. K., Products, T., Maloney, S. F., Products, T., Spindle, T. R., Products, T., ... Products, T. (2018). HHS Public Access, 26(1), 109-112. https://doi.org/10.1136/tobaccocontrol-2015052772.Electronic

Štefanec, T. (2000). Endothelial apoptosis: Could it have a role in the pathogenesis and treatment of disease? Chest, 117(3), 841-854. https://doi.org/10.1378/chest.117.3.841 
Stow, L. R., Jacobs, M. E., Wingo, C. S., \& Cain, B. D. (2011). Endothelin-1 gene regulation. The FASEB Journal, 25(1), 16-28. https://doi.org/10.1096/fj.10-161612

Sussan, T. E., Gajghate, S., Thimmulappa, R. K., Ma, J., Kim, J. H., Sudini, K., ... Biswal, S. (2015). Exposure to electronic cigarettes impairs pulmonary anti-bacterial and anti-viral defenses in a mouse model. PLOS ONE, 10(2), 1-15. https://doi.org/10.1371/journal.pone.0116861

Thomsen, K., Rubin, I., \& Lauritzen, M. (2000). In vivo mechanisms of acetylcholine-induced vasodilation in rat sciatic nerve. American Journal of Physiology. Heart and Circulatory Physiology, 279(3), H1044-54.

Thorne, D., Crooks, I., Hollings, M., Seymour, A., Meredith, C., \& Gaca, M. (2016). The mutagenic assessment of an electronic-cigarette and reference cigarette smoke using the Ames assay in strains TA98 and TA100. Mutation Research - Genetic Toxicology and Environmental Mutagenesis, 812, 29-38. https://doi.org/10.1016/j.mrgentox.2016.10.005

Tyihák, E., Bocsi, J., Timár, F., Rácz, G., \& Szende, B. (2001). Formaldehyde promotes and inhibits the proliferation of cultured tumour and endothelial cells. Cell Proliferation, 34(3), 135-141. https://doi.org/10.1046/j.1365-2184.2001.00206.x

U.S. Food \& Drug Administration. (2016). Vaporizers, E-Cigarettes, and other Electronic Nicotine Delivery Systems (ENDS). Tobacco Products: Products, Guidance \& Regulations: Products, Ingredienst \& Components, 1-5.

US Department of Health and Human Services. (2017). E-Cigarette Use Among Youth and Young Adults: A Report of the Surgeon General. Surgeon General Report, 2. 
van der Poll, T., Keogh, C. V., Guirao, X., Buurman, W. A., Kopf, M., \& Lowry, S. F. (1997).

Interleukin-6 Gene-Deficient Mice Show Impaired Defense against Pneumococcal

Pneumonia. The Journal of Infectious Diseases, 176(2), 439-444.

https://doi.org/10.1086/514062

Wang, L.-S., Wang, L., Wang, L., Wang, G., Li, Z.-H., \& Wang, J.-J. (2009). Determination of Toxic Carbonyl Compounds in Cigarette Smoke. Environmental Toxicology, 24(3), 296-303. https://doi.org/10.1002/tox

Wassmann, S., Baumer, A. T., Strehlow, K., van Eickels, M., Grohe, C., Ahlbory, K., ... Nickenig, G. (2001). Endothelial dysfunction and oxidative stress during estrogen deficiency in spontaneously hypertensive rats. Circulation, 103(3), 435-441. https://doi.org/10.1161/01.CIR.103.3.435

Weksler, B. B. (1981). Arachidonic Acid Cascade : The Cyclooxygenase Pathway, 2(2), 1981.

William, B., Thomas, R., Sandra, H., Doyle, J., \& Dawber, T. (1964). The relationship of cigarette smoking to coronary heart disease. JAMA: The Journal of ..., 190(10), 109-112.

With, P., \& Artery, C. (2018). Ascorbic Acid Reverses Endothelial Vasomotor Dysfunction in, 116.

Wu, Q., Jiang, D., Minor, M., \& Chu, H. W. (2014). Electronic cigarette liquid increases inflammation and virus infection in primary human airway epithelial cells. PLoS ONE, 9(9). https://doi.org/10.1371/journal.pone.0108342

Yang, S., Chida, A. S., Bauter, M. R., Shafiq, N., Seweryniak, K., Maggirwar, S. B., ... Rah-, I. 
(2006). Cigarette smoke induces proinflammatory cytokine release by activation of NF- B and posttranslational modifications of histone deacetylase in macrophages, 14642, 46-57. https://doi.org/10.1152/ajplung.00241.2005.

Yong, T., Zheng, M. Q., \& Linthicum, D. S. (1997). Nicotine induces leukocyte rolling and adhesion in the cerebral microcirculation of the mouse. Journal of Neuroimmunology, 80(1-2), 158-164. https://doi.org/10.1016/S0165-5728(97)00151-3

Yuan, Y. M., Luo, L., Guo, Z., Yang, M., Ye, R. S., \& Luo, C. (2015). Activation of reninangiotensin-aldosterone system (RAAS) in the lung of smoking-induced pulmonary arterial hypertension (PAH) rats. JRAAS - Journal of the Renin-Angiotensin-Aldosterone System, 16(2), 249-253. https://doi.org/10.1177/1470320315576256 